مجلة جامعة الملك عبدالعزيز: الآداب والعلوم الانسانية، م29ع3 ص ص: 28- 54 (2021م)

DOI:10.4197/Art.29-3.2

\title{
استراتيجيات السرد في أدب ما بعد الحداثة: رواية "بيت أوراق الثجر" لمارك ز • دانييلفسكي أنموذجًا
}

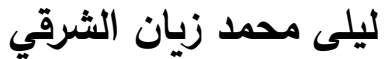 \\ قسم اللغات الأوروبية وآدابها - كلية الآداب والعلوم الإنسانية \\ جامعة الملك عبد العزيز
}

مستخلص. تعتبر رواية "بيت أوراق الثجر" للروائي مارك ز ـ دانييلوسكي أحد أهم الأعمال في أدب الرواية المعاصر .

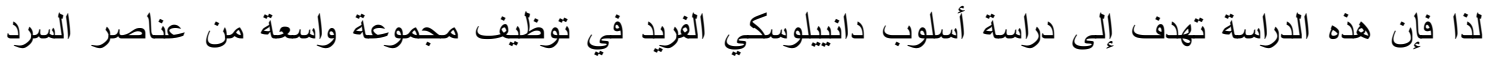

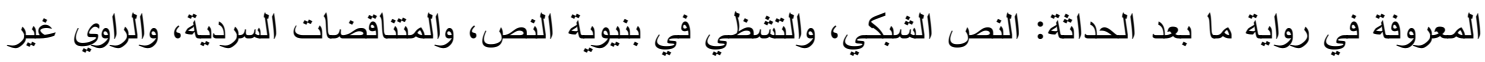

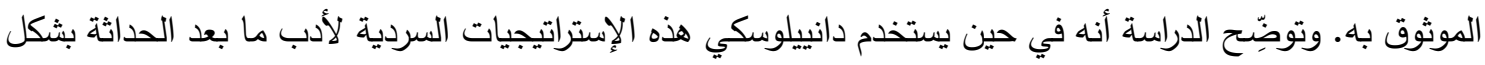

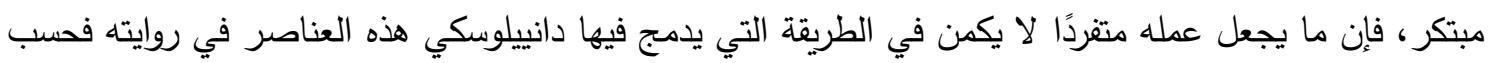

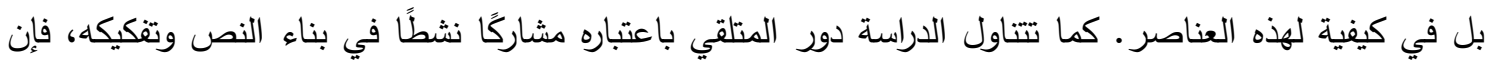

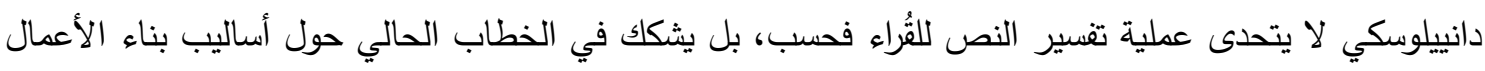

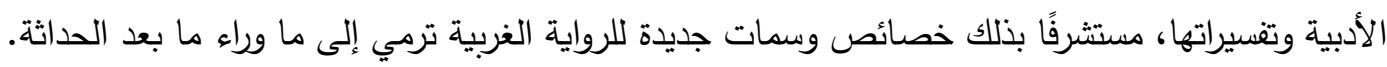

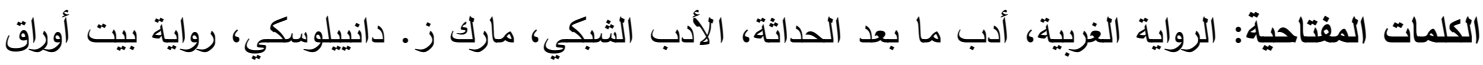

الثجر - الثر

ومضمونها، معتمدة في ذلك على البعد عن التقليدية

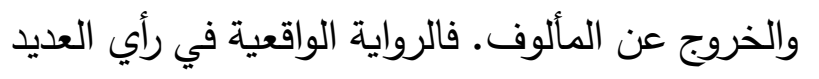

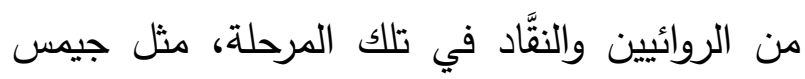
جويس وفرجينيا وولف، انفصلت عن الواقع ولم تعد

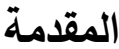

شهدت الرواية الغربية بداية القرن الماضي محاولات عدة لتقويض الأساليب الأدبية السائدة في الرواية الواقعية. إذ سعت إلى اكتثاف آفاق جديدة في شكلها 
والدينية والأخلاقية ويحولها إلى عبث مطلق، هذا الخطاب أدَّى إلى انهيار اليُّل العليا والقيم الأخلاقية

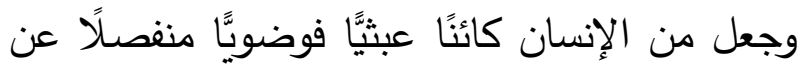

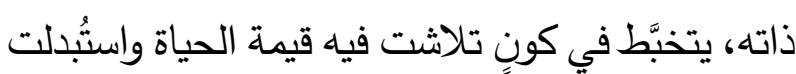
بقيمة الموت التي عبَّر عنها نيتشه بفكرة موت "الإله". انعكست هذه المفاهيم الفلسفية على شتى العلوم بما فيها الأدب الذي استمد قيمه من هذه المفاهيم لتصبح النزعة العدمية إلى تفكيك وحدة البناء وهدم الأنساق القيمية والثقافية المكونة للذات والجماعة من أبرز

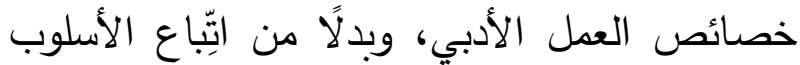
السردي المتماسك والحبكة الروائية وإبراز تطور الثخصيات، وتثبيت المرجعية الزمانية والمكانية

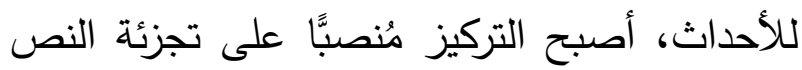

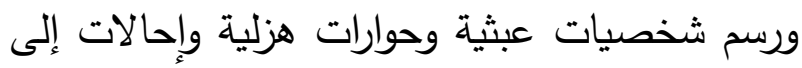
نصوص أخرى بهدف تكريس الفوضى والتشظيّي وخلق والقي مستويات متعددة من السرد وإضفاء حالة من الثك

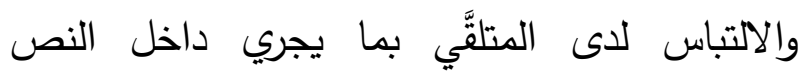
(هوفمان2005 ، ص 74-71). ومن أبرز التقنيات

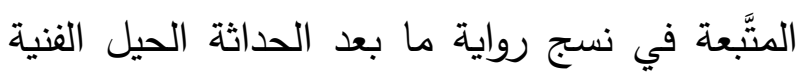
والسردية مثل التشظِّي وأسلوب ما وراء القصّ والواقعية السحرية والمفارقات السردية والتتاص، هذا بالإضافة إلى إغراق النص في وقائع تاريخية وقيم مطلقة لا لتأييدها بل لزعزعتها وتقويضها من جذورها، والتهكُم والسخرية من الأيدولوجيات واعتبارها هواجس فكرية فارغة، وعادة ما يكون توظيف هذه التقنيات وغيرها ليس لخلق تجربة روائية ممتعة بل تعمل على بث
تتناسب مع روح ومستجدَّات العصر الحديث. فمظاهر التطور الصناعي والتتني ونتائج الحرب العالمية الأولى فرضت أساليب وفلسفات جديدة من التنكير وأنماطًا مبتكرة من السرد الأدبي حلَّت محل أنماط الَّات من الفكير وخصائص السرد الواقعي كالإسهاب في وصف

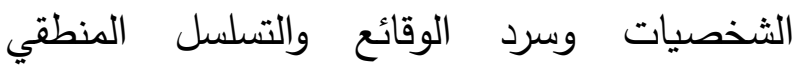
للأحداث. إذ ركزت الرواية الحداثية على الذاكرة الفردية وإظهار التفاعلات النفسية للشخصيات وما يعتريها من تطورات بدلًا من إظهار علاقتهم بالمجتمع، مثال على ذلك رواية جيمس جويس "عوليس 1922" ورواية فرجينيا وولف "مسز دالوي 1925" اللتان اعتمدتا على "تيار اللاوعي" أسلوبًا سرديًا (كويجلي 2015، ص 5-1920) مع مطلع النصف الثاني من القرن الماضي وإبان الحرب العالمية الثانية، اتخذت الرواية منعطفاً أكثرحِة، إذ ازداد تحررها من الأنماط السردية التقليدية

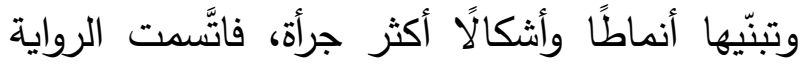
الغربية في هذه الحقبة بثرتها على قواعد وجماليات الكتابة الأدبية والسرد في الرواية الواقعية والرواية الحداثية. وبينما تعددت مسميات رواية ما بعد الحداثة، إذ أطلق عليها بعض النقاد مسهى "الرواية التجريبية"،

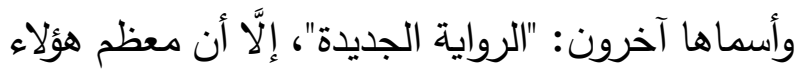

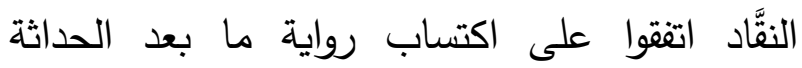

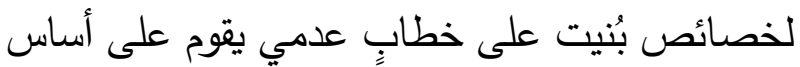
تقويض النظام وتغييب المنطق وهدم المعنى، ويعتمد على منهج فوضوي يثكك بالثوابت والمسلمات الكونية 
تتدهور حالة تروينت النفسية ويصبح فريسة للأوهام والهواجس والبيت ذي المتاهات الذي يؤذي كل من لن لهن يحاول اكتشافه وسبر أغواره.

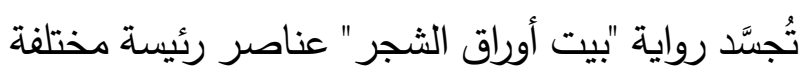

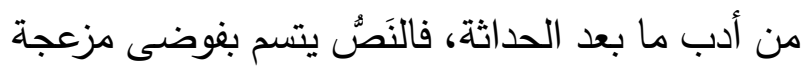

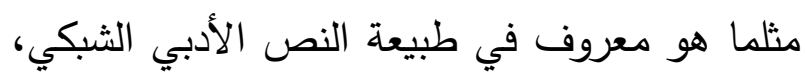

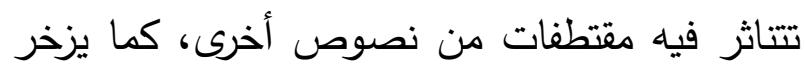

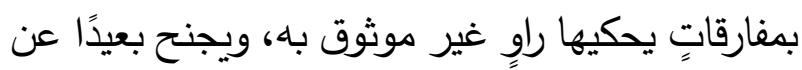

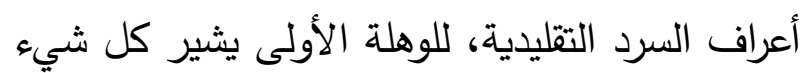

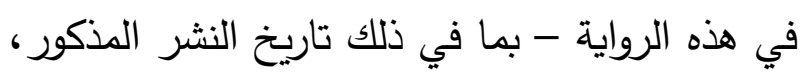

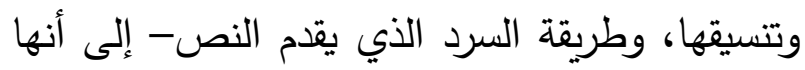

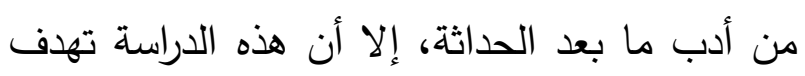
إلى توضيح أنه في حين يستعمل دانييلفسكي الإشارات

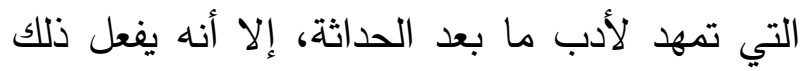

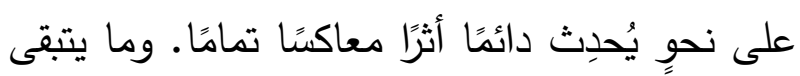
للقارئ - بعد البحث العميق في "بيت أوراق الثجر "-

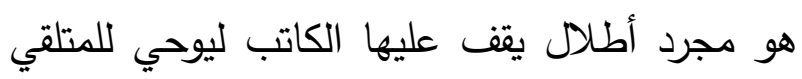
بعبثية محاولته لفك الثفرات والرموز المتضمنة في لئ الرواية وأن مآله سوف يكون مثل مآل شخصيات الرواية، إما الجنون أو الموت. في الواقع تعد رواية "بيت الأوراق" نهاية ما بعد الحداثة الثات

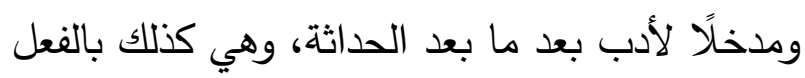
من حيث الطريقة التي تَعَّد فيها الكاتب إلى تغيير

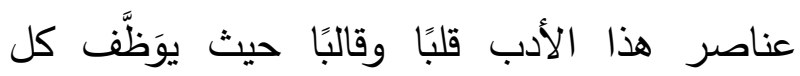
عناصر أدب ما بعد الحداثة في روايته ثم يقوّضها لهاديا
الفوضى في النص إما لتشتيت ذهن المتلقي أو لتحفيز

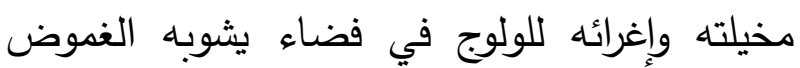
وتتخلله نصوص أخرى متعددة (هتشيون 1988). تُعد رواية "بيت أوراق الثجر" المنشورة في عام 2000 الرواية الأولى لمارك ز. داند دانييلفكي والتي تقع في (709) صفحة، نموذجًا فريدًا لرواية ما بعد الحداثة. وتدور أحداث الرواية حول عثور بطل الرواية جوني تروينت على مخطوطة لرجل كفيف يدعى زامبانو، تحتوي على بحث يدرس وثثية أخرى بعنوان: "مقال نافيدسون" لكاتب يدعى ويل نافيدسون، وتحكي الوثيقة

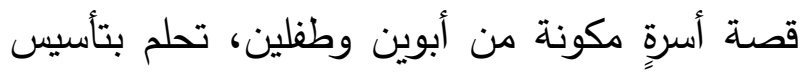
بيت جديد والاستمتاع بحياة أخرى بعد مرور الأبوين بمشاكل زوجية، لكن يبدو أن لمساحة هذا البيت ذاتها حياتها ومقاصدها الخاصة بها، فبعد انتقال العائلة إليه، وما إن تبدأ الألفة في التسرب إلى نفوسهم، يدرك الأب أن داخل هذا البيت ظاهرة غرببة حيث يشغل

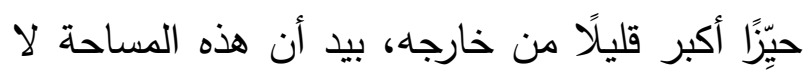
تلبث أن تتزايد إلى أن يصبح بيت الأسرة أقلَّ أُلفة وينشئ من تلقاء نفسه أبوابًا وممراتٍ تمتد لأميال

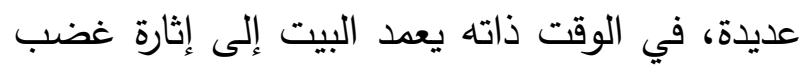

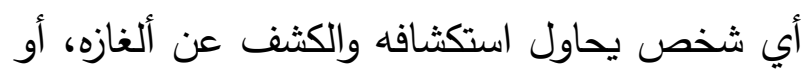
يعمد حتى إلى قتله، وأثناء قراءته للوثيقة يقوم جوني تروينت بكتابة قصته ومجريات حياته اليومية المليئة بالدغامرات العاطفية على شكل حواشٍ وتذييلات جانبية على مقال نافيدسون إضافة إلى كتابة آرائه الثخصية عن المخطوطة، وأثناء قراءته للمخطوطة 
طبيعة ارتباط شبكي، لا تضم - خلاف تلك التلميحات - سوى القليل مما يُنسَب إليها بالكامل، حتى وإن إن

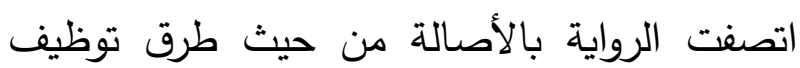
عناصر أدب ما بعد الحداثة. إذ إنه وبعد تفكيك هذه لرواله

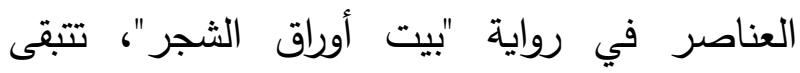

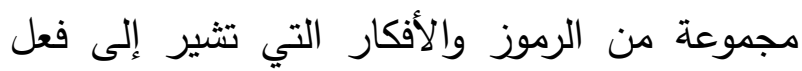
القراءة ذاته، وهي في مجملها تساعد المتلقي في إعادة تقييم أسلوب القراءة وكيفية التفاعل مع النص. تهدف الدراسة إلى التعرف على الأسباب التي دفعت بالكاتب إلى استعمال هذه المكونات السردية، وكذلك تسليط الضوء على الطريقة التي يَنْخَر بها دانييلفسكي من هذه العناصر، وكيف أنه بفعله هذا يهدف إلى لى لـي

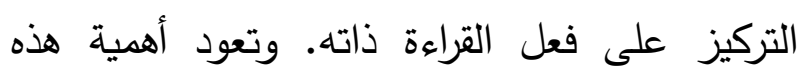
الدراسة إلى عدة أسباب، أهمها: قلة الأعمال النقدية عن رواية ما بعد الحداثة الغربية

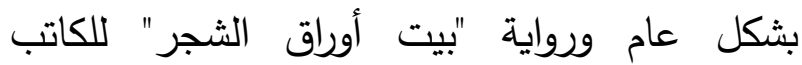

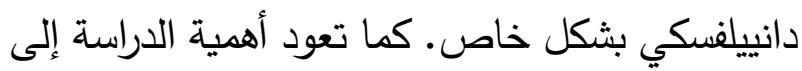
توضيح كيف أن هذه الرواية من خلال استراتيجيتها السردية المتميزة وخصائصها وثيماتها تُعد استشرافًا لنهاية حقبة ما بعد الحداثة وبداية عصر جديد ومدخلاً مهمًا للرواية المعاصرة أو ما يُعرف برواية ما بعد لئد الألفية. - ملية تبدأ هذه الدراسة أولًا ببحث كل عنصر من عناصر

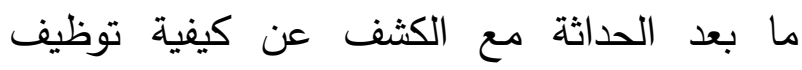
دانييلفسكي لكل منها في "بيت أوراق الثجر "، ومن ثم ثند تناقش هذه الورقة استيعاب دانييلفسكي المبهر
جميعًا ليطرح تساؤلاته عن معنى الكتابة والتأويل كما يقول ويليام ج. ليتل: "قد يكون بيت الأوراق نصًا لما بعد الحداثة مرتبطًا

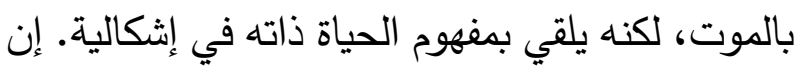
محاولة تصنيف "بيت أوراق الثجر" على أنها روايةٌ لئه لما بعد الحداثة أو على أنها -ـوضوح- شيءٌ آخر

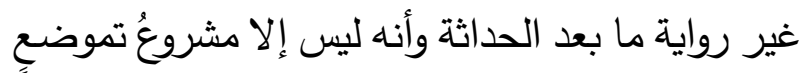
يؤدي، كما يبدو لي، إلى طريق مسدود." (ليتل، 2007، ص 170، 170). تسعى هذه الدراسة إلى التعرَّف على أهم العناصر

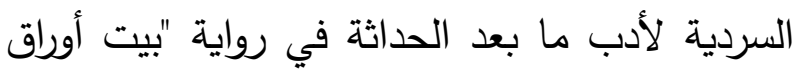

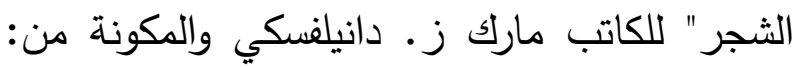
التثظي والمفارقة والراوي غير الموثوق به والسرد الماورائي. وباتِّاع منهج الوصف التحليلي ستقوم الدراسة بفحص كل عنصر من هذه العناصر عن كثب لتتبََ أن "بيت أوراق الثجر" تعد نموذجًا فريدًا لرواية

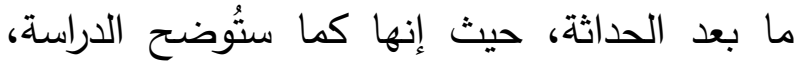
تُوظف هذه السمات والعناصر ليس من أجل ترسيخ أو اعتناق الأسلوب الروائي لأدب ما بعد الحداثة، بل

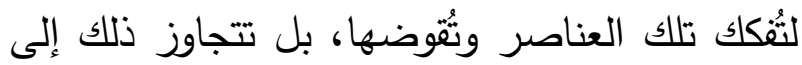
السخرية منها، حيث يعمد دانييلفكي إلى وإفراغ

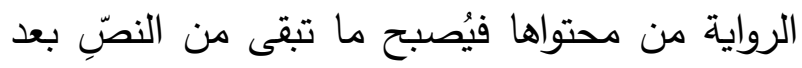

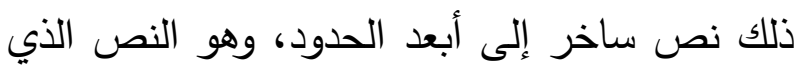
يشير إلى أهمية عملية القراءة ذاتها، ففي داخل هذا النص الساخر ، يجد المتلقي رواية تتكون إلى حد كبير من إثارات إلى نصوص أخرى، وهي رواية ذات 
وعائلته حين يكتشف هو وأفراد العائلة تغيرًا في المنزل

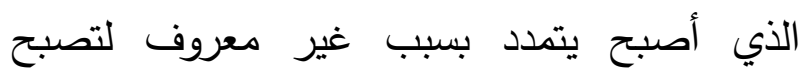
مساحاته الداخلية أكبر من مساحته الخارجية بعد أن تحولت ممرات المنزل إلى متاهات وغرف إضافية. ويسجل التقرير محاولات ويل نافيدسون تصوير هذه الظاهرة الغريبة بالإضافة إلى مناقثات أكاديمية

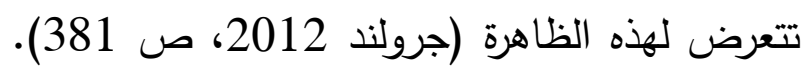
ويرتبط النص الثاني بالنص الأول فهو يدور حول قصة رجل كفيف يدعى زامبانو ومخطوطة عن فيلم بعنوان: "تقرير نافيدسون" والتي يقوم زامبانو بكتابتها للتعليق على "تقرير نافيدسون"، كما يقوم زامبانو

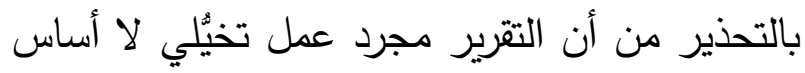

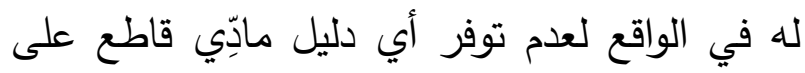

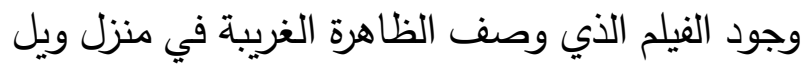
نافيدسون (دانييلفكي 2000، ص ص 19). أما النص الثالث فكتب على هيئة هوامش كتبها محرر المقال جوني تروينت، موظف متجر الوشم الذي هاني

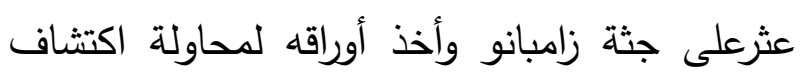

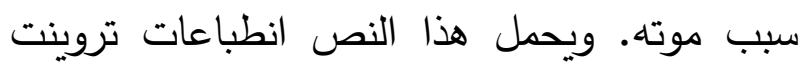

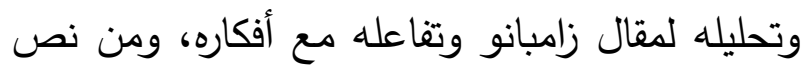
تروينت الأصلي تتفرع نصوص أخرى تتناول علاقة

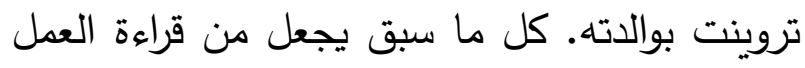

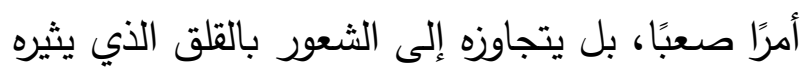

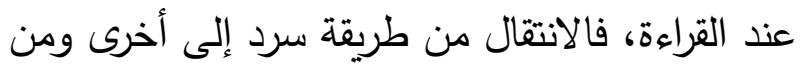

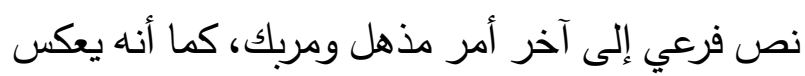

لخصائص رواية ما بعد الحداثة وتقديمها بشكل مُحكم ومُتداخل تعمل على تكوين البناء العام لنص الرواية، وهو ما يسمح له بتفكيك وهدم تلك الخصائص، والتعبير ضمنًا عن أن هذا الهدم هو ما يهدف إليه

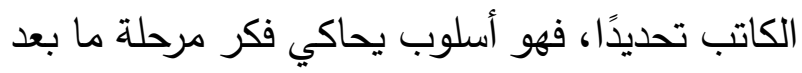
الحداثة المتمثل في الاستجواب الوجودي والثورة على في الكلون المألوف ونقض الثوابت، وفي الوقت ذاته يطرح تساؤلات نقدية وفلسفية تدور حول جوهر اللغة والكتابة والتأويل. تصولات

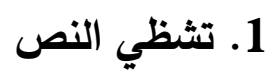
أحد أهم استراتيجيات السرد التي يطبِّّها دانييلفسكي

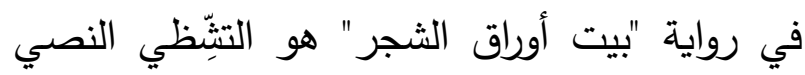
الواعي، ويأتي في هيئة روايات متعددة تضم كل واحدة منها العديد من النصوص الفرعية والمرجعيات والنصوص الماورائية خلافًا للرواية التقليدية المحتوية على بنية سردية تصاعدية ومتكاملة من حيث تسلسل وحبكة القصة بما يتوافق مع تطور الأحداث

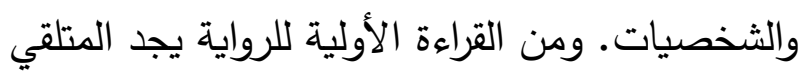

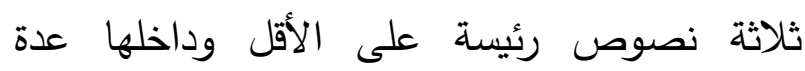
نصوص فرعية، أما النص الرئيس الأول فهو "تقرير نافيدسون الذي يحتوي على عرض وتحليل لظاهرة

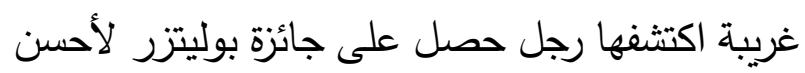
مصور يدعى "ويل نافيدسون" الذي انتقل هو وزوجته

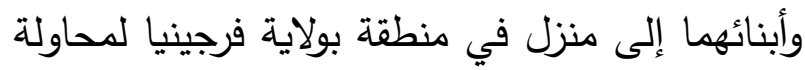
إنقاذ علاقتهما من الفشل، يتمحور هذا التقرير حول فئل عرض ظاهرة تمدد المنزل الذي يقطنه ويل نافيدسون 
ويأبى دانييلفكي إلا أن يقلب شكل الرواية التقليدي

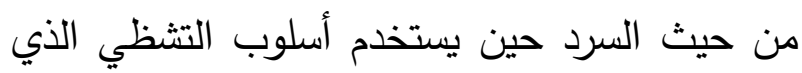

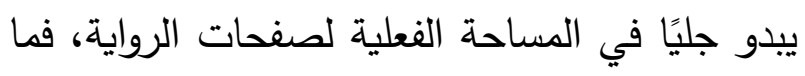

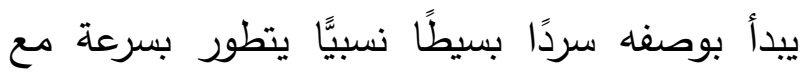

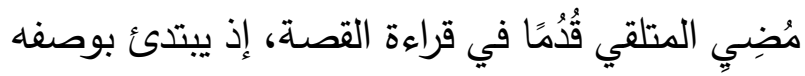

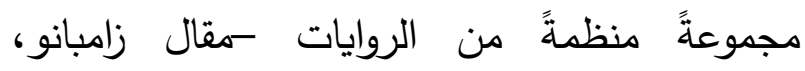
والحواشي السفلية لتروينت، وأحيانًا الهوامش التحريرية في الحواشي السفلية لتروينت- ثم يأخذ النص في التشعب والتداخل، شاقًّا طريقه داخل الصفحات بشكل فوضوي ليعكس الاضطراب الفعلي الموجود في حياة

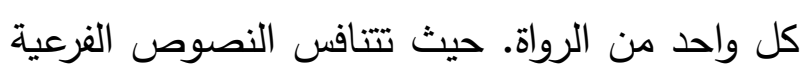
مع النصين الرئيسيين لأخذ حيز من الصفحات، سواء حلئ كانت حواشٍ سفلية في صندوق (دانييلفسكي، 2000،

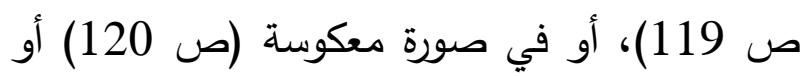
مقلوبة (ص 121). ومع ازدياد حجمه، يتوظلَّف هذا

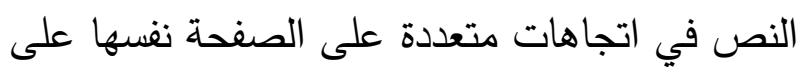
نحو متكرر، فيبدأ المتلقي في ملاحظة المسافات في منعات عادي

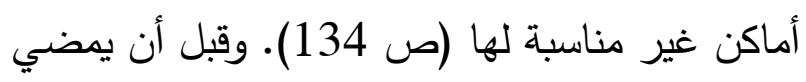
وقت طويل، تظهر صفحات كاملة لتخالف توقعات المتلقي (ص 144، على سبيل المثال). ثم ما يلبث أن يصل إلى الفصل العاشر ليجد أن المساحة

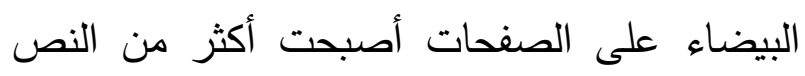
نفسه (153-245)، وتتكوَّن جمل متعددة تحتل كل واحدة منها صفحات عديدة، مثال على ذلك ما يكتبه

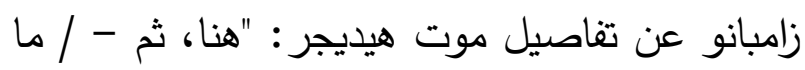

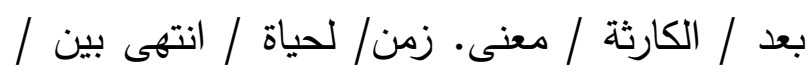

حالة التشتت والضياع التي تعيشها كل شخصية في رواية "بيت أوراق الثجر". ينعكس هذا التشظّيّي بشكل واضح على رولى شخوص النصوص الثلاثة الأساسية والفرعية: فتنكك أسرة

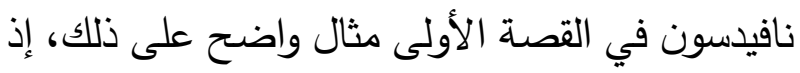
لم يقتصر الأمر على وصف أحد أفرادها حرفيًا بالممزق - "العظام مثل أعواد الخبز [كلمات ريستون] تخترق اللحم الآن..." (دانييلفسكي،2000، ص صل 346) - بل إن أسرة نافيدسون بأكملها تتمزق أوصالها في البيت الذي أصبح كالمتاهة، لاحظ أيضًا استعمال زامبانو لهييديجر في تعريف البيت "أثناء القلق، يشعر لهري

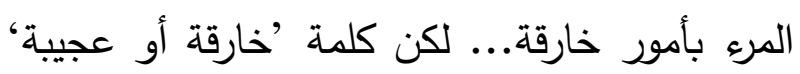
هنا أيضًا تعني: "الثعور بالغربة في البيت" جراء هذا التمدد العجيب للبيت (دانييلفكي، لهي، 2000، ص 25 25). إذ على الرغم من أن زامبانو يمضي قُدُمًا في استخدامه

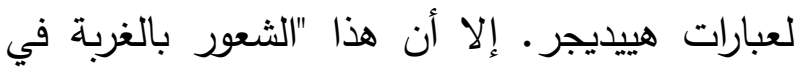

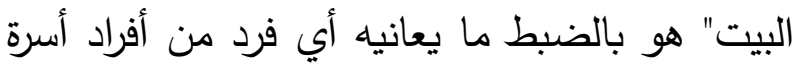
نافيدسون من تثظي وتثتت نتيجة صدمتهم من البيت ومن حالة التيه التي يعيثونه؛ والتي ما لبثت أن أن تحولت آثارها إلى تقويض نفسي باتوا يعيشونه تجاه أنفسهم والمحيطين بهم في المنزل، وعلى النحو نفسه، فإن التشظِّي في السرد نفسه يعمل على تشظي أفكار المتلقي وتفكيكها وعلى إقصائه بعيدًا عن أي محاولة لفئل يقوم بها لفهم النص لَيجدَد في النهاية أن الرواية كلها لفها مفككة في زخمٍ فوضويٍّ من التلميحات والارتباطات الثبكية والرموز - والتي تدل على فعل القراءة ذاتها. 
تثبه إلى حدّ ما تقنيات الأفلام (بولمان، 2012، ص

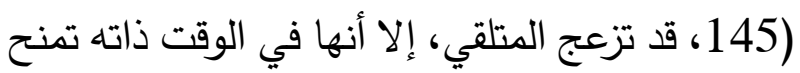

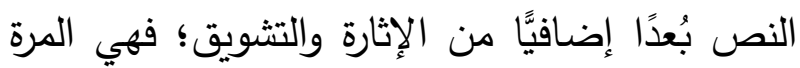

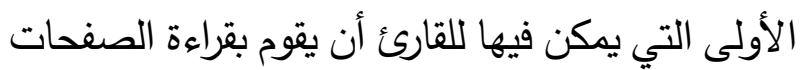

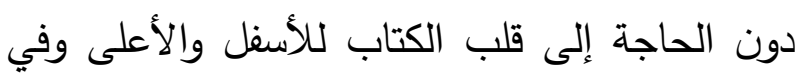
مختلف الاتجاهات، ومع ذلك فإن غرابة طريقة السرد

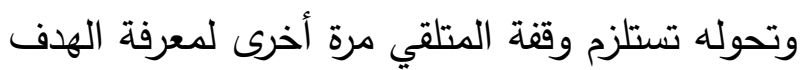
من تزويد المتلقي بعبارات أو معانٍ تبدو واضحةً ومباشرة عبر هذه الصفحات شبه الفارغة .
مساحة/ لإطارين" (دانييلفكي، ص 193-201)، هذه العبارة البسيطة التي تشغل مساحة اثنتي عشرة

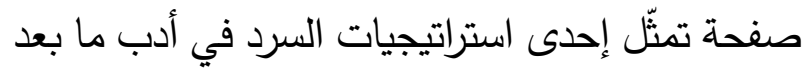
الحداثة، تتلخص فيما أشار إليه أرفانتيس وسكوردوليز (2008): "نجد أنفسنا في نظام كبير لدرجة أن أن

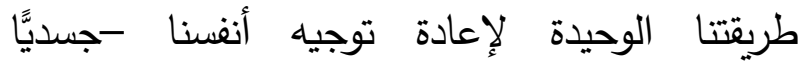
واجتماعيَّا- هي بتوظيف طريقة رسم خريطة أنفسنا مكانيَّا" (ص 110 110. هذه الآليات غير التقليدية في

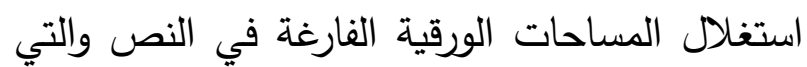

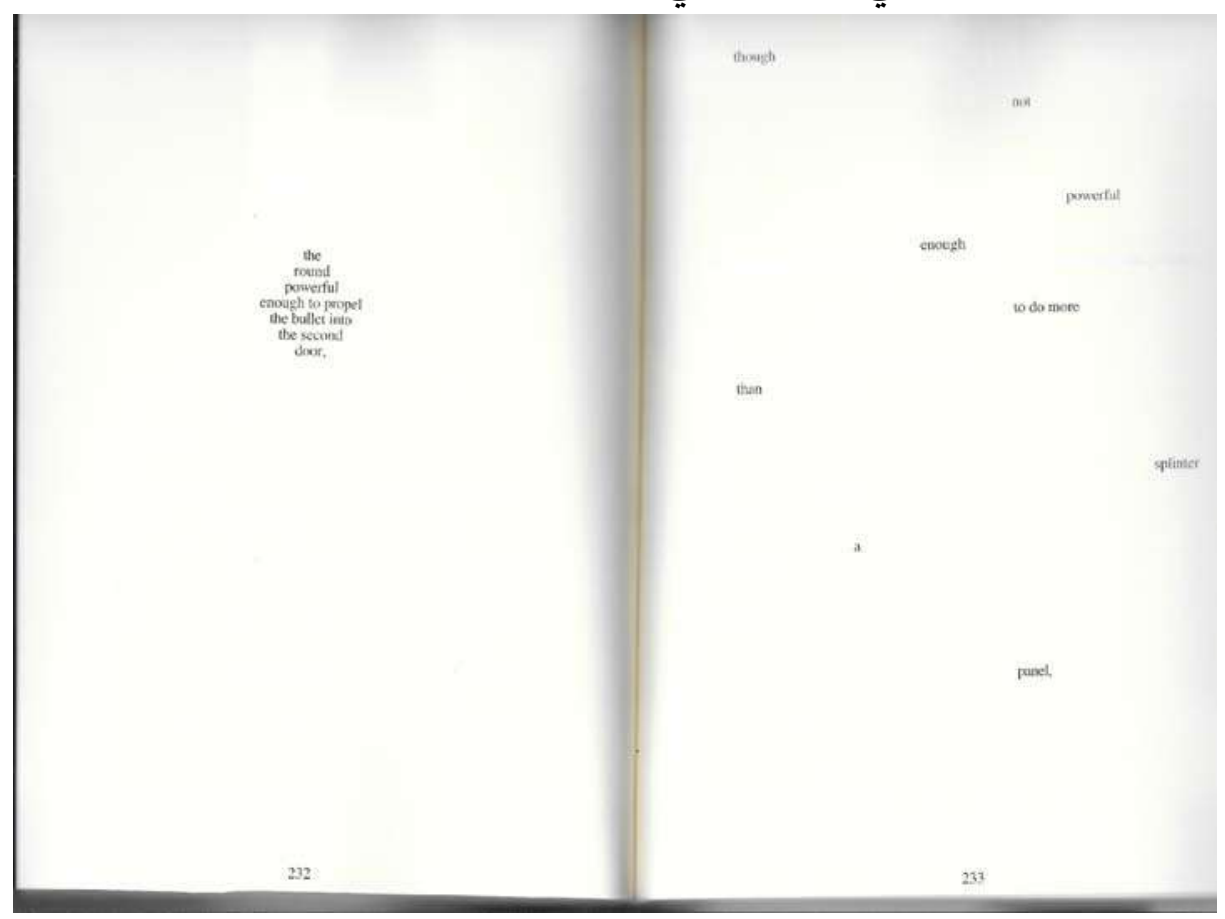

شكل 1. مساحات شبه فارغة من صفحات في رواية "بيت أولق الثجر" تمثل الحالة النفسية للثخصيات والمتلقي

بطبيعة الحال، فإن زامبانو ليس هو الراوي الوحيد الذي وما يرويه من تفاصيل دقيقة، ففي كثير من الأحيان،

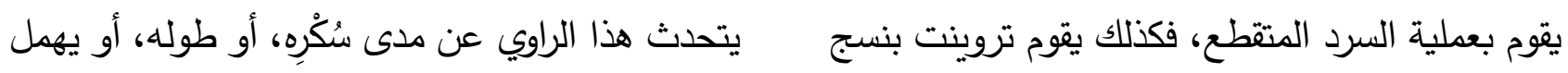

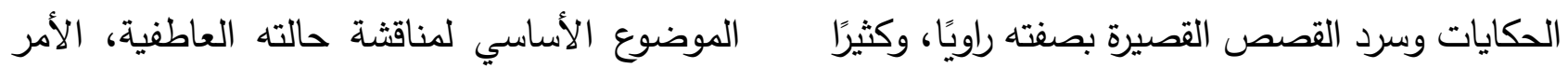
ما يواجه المتلقي صعوبة في تحديد المكان والزمان الذي يجعل المتلقي في حالة تأهب دائم لمعرفة كيفية 
كل هذه الأساليب السردية ليست بسيطة، وإنما هي

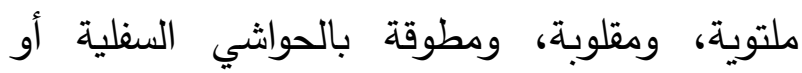
المساحات البيضاء غير الطبيعية. وهذا مالا يتوقعه

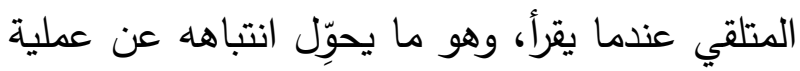
القراءة ذاتها إلى محاولات لتفسير ما يوجد على

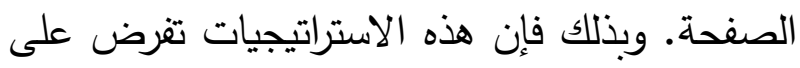
المتلقي أن يقرأ بطريقة تجعله أكثر وعيًا بعملية القراءة

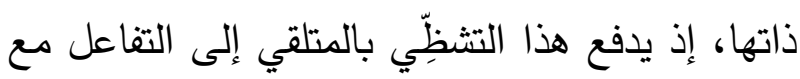

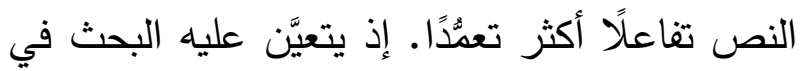
كل جزء من مكونات الكتاب على حدة، ويعزم على اتخاذ قرار في كيفية تجميع تفسيره للنصوص الأصلية والفرعية منها بوعي مدركًا قصدية الكاتب في اعتماد هذا الأسلوب السردي، وكيف يكوِن نظرته للعوالم المطروحة في رواية "بيت أوراق الثجر"، وهكذا يتناول

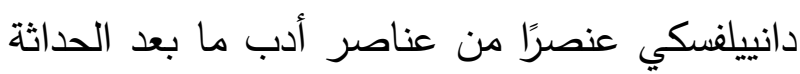
(وهو التشظي) ويطبِّه على نصه بطريقة تدفع المتلقي إلى التساؤل عن السبب وراء استعماله إياه، إذ ما الذي لئي

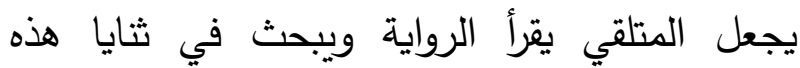

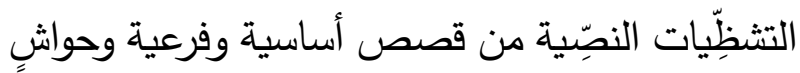
وتذييلات في النص بشكل متعدد إن لم يوجد هناك

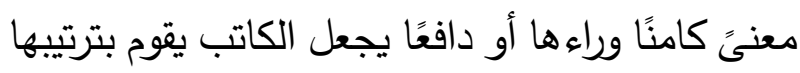
بهذا الثكل؟ إن ما يستنتجه المتلقي من دراسته لاستخدام الكاتب أسلوب التشظي في النص هو أن لن دانييلفكي يجبر المتلقي على الإلمام بمختلف مكونات النص أساسية كانت أو فرعية من أجل تكوين

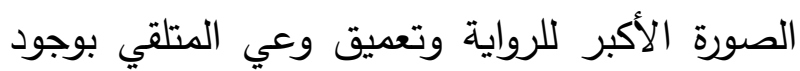

قراءة هذه القصص التي يسردها وتتبع أفكاره. وهذا ما سيتم مناقشته بإسهاب في الجزء المخصص لتناول إستراتيجية دانييلفكي في استخدام الراوي غير

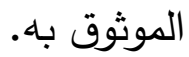

وأخيرًا: نجد أن أسلوب التثظي هذا وهو إحدى لهى السمات الرئيسة لرواية ما بعد الحداثة يبدو في ثيمة

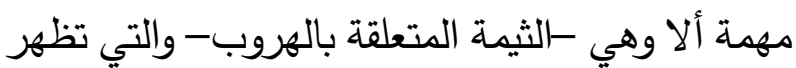
في مكالمات طلب النجدة، والإشارات المتكررة إلى أغنية البيتلز "Help"، وغيرها من الرسائل المُرَمَّزَة، والمجزأة وغير المنتظمة، فكالمات طلب النجدة تبدأ في الفصل السابع بمقدمةٍ عن نداء الاستغاثة من قاموس أوكسفورد للغة الإنجليزية (دانييلفكي، 2000، ص 97)، حيث يلجأ المؤلف إلى استهلال كل قسم في الفصل برمز مورس لنداء الاستغاثة مستعملً ثلاث شرطات قصيرة، متبوعة بثلاث

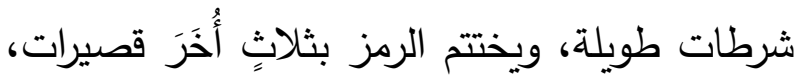
ينقسم الفصل نفسه -مثله مثل الرمز - إلى ثلاثة أقسام قصيرة، متبوعة بثلاثة أقسام طويلة، ثم ثلاثة أُخر قصيرة. "لاحظ كيف يتتقل نافيدون بين الأقسام

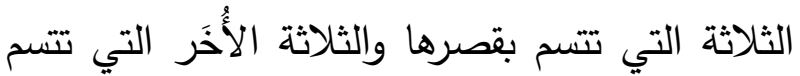

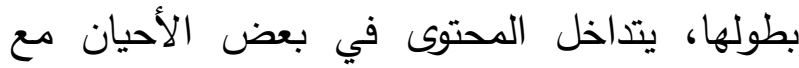
الإيقاع الروائي، إلا أن النمط المنَّع في تنظيم الأقسام لا يشوبه خطأ" (دانييلفكي، 2000، ص إلان 102). بعد عرض هذا النظم المتكرر، تتلاشى تقريبًا الإشارة

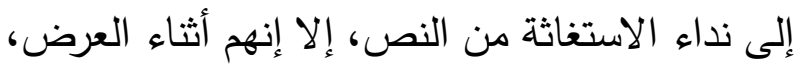
يتطرقون إلى ذكرها ذكرًا عابرًا . 
للنص مع العمل، الأمر الذي يؤدي بدوره إلى تكامل

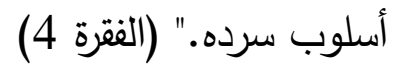
بهذا التعريفات الأولية يمكن القول بأن رواية "بيت

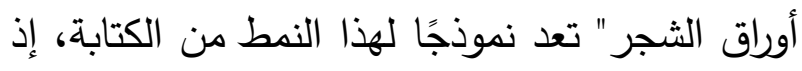
تتميز الرواية بأسلوب السرد المتعدد، فقصة تروينت ومقال زامبانو هما الروايتان الرئيستان، لكن هنالك لكئل

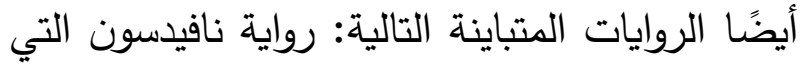
يجد المتلقي نفسه فيها بمعزل عن زامبانو، وعلاقة تروينت بوالدته ببيلافينا، التي يتم التعرف عليها من بن

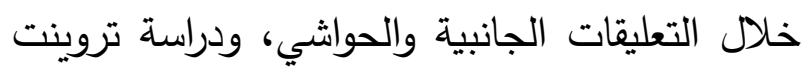

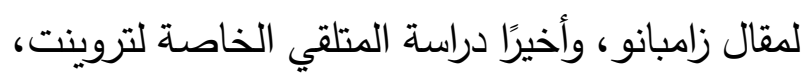

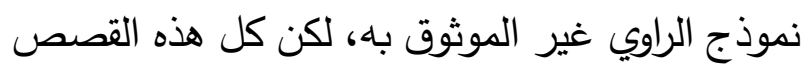

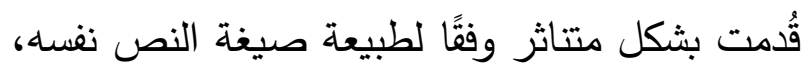
بالإضافة إلى ذلك، لا يمكن للقارئ إكمال القراءة وجمع خيوط القصة دون أن يقوم بجمع أجزائها المتناثرة في أجزاء الرواية. يبدو النمط الثبكي جليًا في تكرار لون الخط المستخدم الثراه (الأزرق) عند وصف البيت في في الرواية (دانييلفكي،2000، ص 24، 117، 399، (الازوف) كما يظهر في النص استخدام ألوان أخرى كاللون

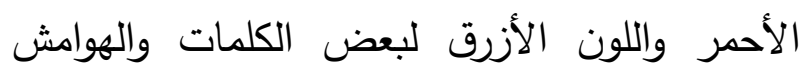

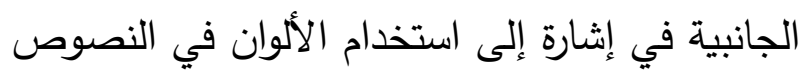
الإلكترونية الثبكية (دانييلفكي 2000، ص إنساري 109، 111، 110، 119، 338). كما أن وصف بيت نافيدسون يشير أولًا إلى شاشة زرقاء ونظام إلكتروني يعمل بالضغط على مفتاح تشغيل يشير إلى نقطة لئل
هذه الصورة وبالمشاركة في رسمها من خلال الغوص في عوالم النص الداخلية والتفاعل مع صرهاعتاته المتوالية، ففعل القراءة في حد ذاته، وتتاول كل صفحة

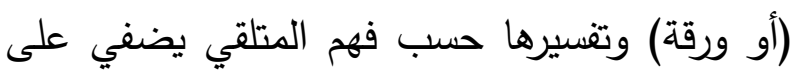
عملية القراءة طابعًا مميزًا. 2. النص الثبكي (السبراني) للتعرف على طبيعة النص الشبكي يقدِّم إسبن آريث في عمله النص الثبكي: (تتظيم النص من أجل تحليل تأثير الوسيلة بوصفه جزيًا لا يتجزأ من الديناميكية الأدبية) تعريفًا للنص الثبكي على أنه نص يتطلب

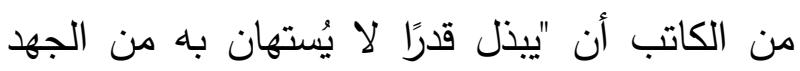

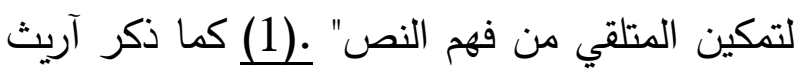
ثلاثة أوجه شبه رئيسة بين النص الأدبي غير التقليدي

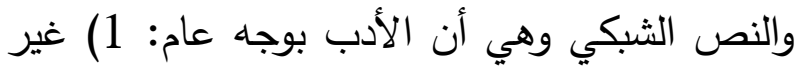
محدد، ويختلف باختلاف المتلقي؛ 2) أنه على المتلقي القيام بخيارات من أجل أن يتمكن من فهم النص؛ 3. 3. أنه لا يمكن للنص أن يكون بالفعل لأن المتلقي يمكنه قراءة النص في تسلسل واحد فقط في كل مرة، ذلك لك لكان لأن "التكامل" هو الهدف من العمل الأدبي غير فئل التقليدي، ويشمل هذا تكامل السرد، وتكامل الأغراض، وتكامل الأسلوب (آريث، 1997 ص صنئبل 2، 19-20). كما يقول جيسون ويدمان (2000): "تتمثل التعقيدات هنا في أن المنحنى السردي للعمل في أدب الإيرجودِك أو الأدب الشبكي غير محدد ويتأرجح في نطاق البناء

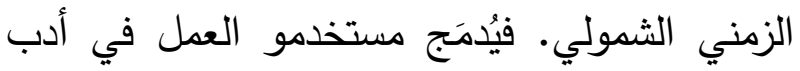
الإيرجودِك بطريقة تُوحي بتكامل الأساليب الوظيفية 
تماماً مثل ما تتيح النصوص الثبكية ذات الفرصة

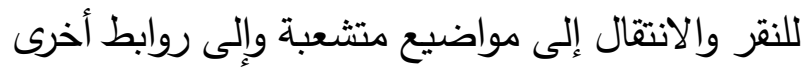
متصلة، وهي في هذا تشبه ما تحويه صفحات الرواية حيث إنّ كل صفحة لا تثير إلى ذاتها فقط، بل تمتد

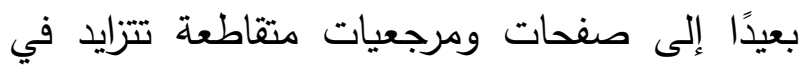
الاتساع لتكون شبكة من الأفكار المتنامية بلا نهاية والتي تحمل الكثير من التلميحات الضمنية والرموز

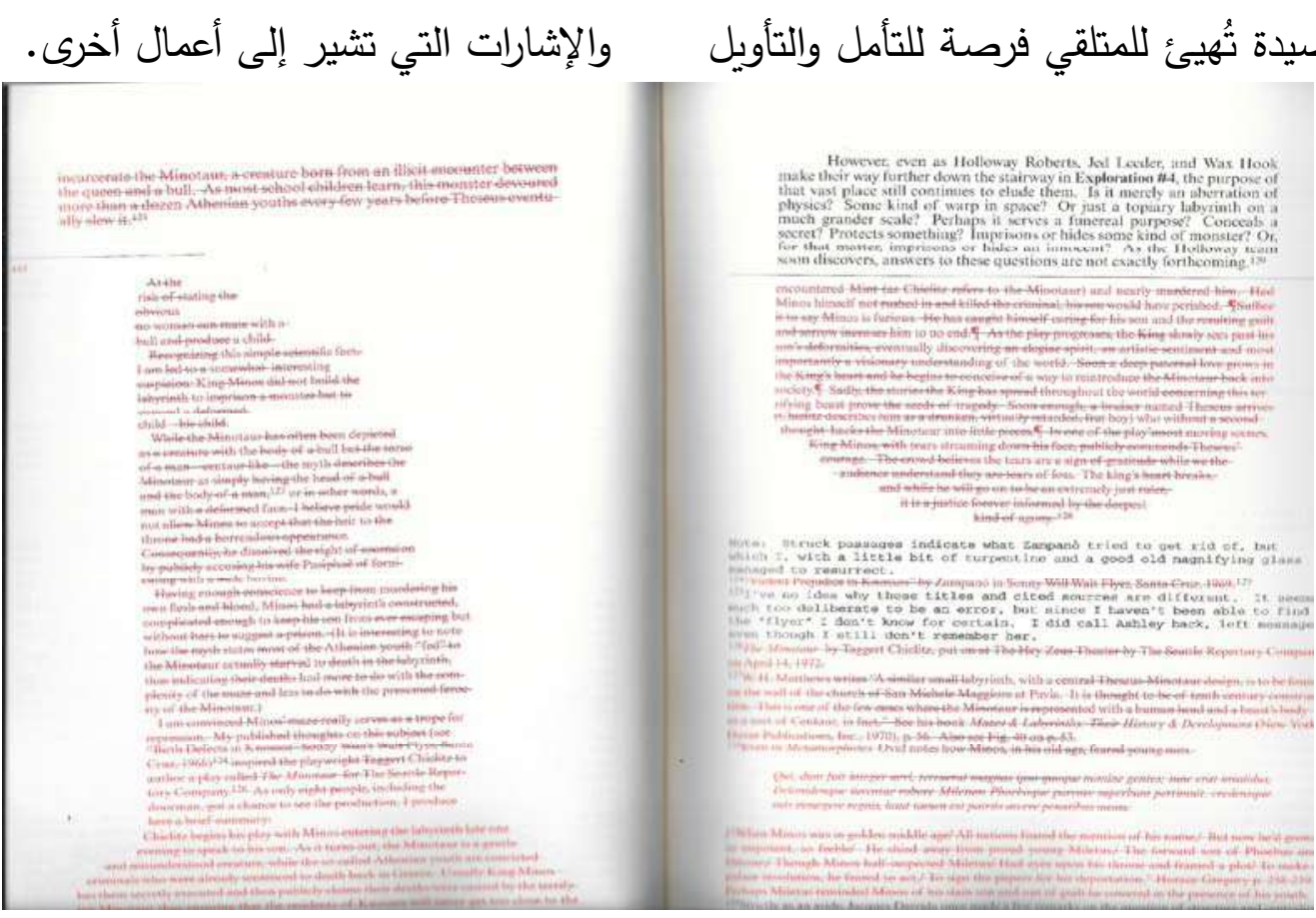

البداية والنهاية أو الانطلاق والرجوع، وهو ما يرمز

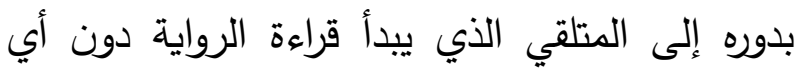
توقعات ثم يعود إلى نقطة البداية، الأمر الذي يتكرر مرارًا في الرواية ليعمل ضمن إطار محدد لتعزيز

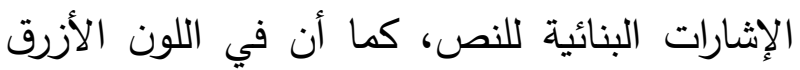
إثارة إلى الارتباطات الثبكية في معظم صفحات

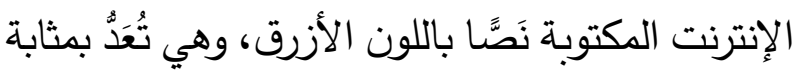

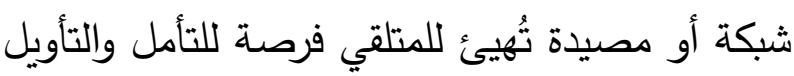

شكل 2. صفحات في رواية "بيت أورلق الثجر" تحاكي النصوص الثبكية في صفحات الإنترنت

لا يطلب دانييلفكي من متلقي رواية "بيت أوراق الثجر" أيَّا من ذلك على الرغم من احتواء أجزاء كثيرة

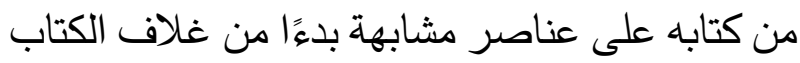

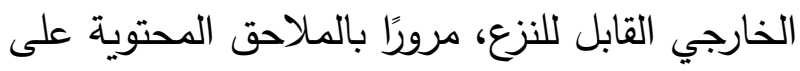
الصور التوضيحية ومجموعة من الأشعار مجهولة

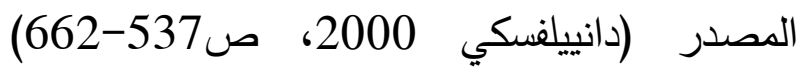

وفي حين يطلب كتَّاب بعض روايات ما بعد الحداثة في أدب الإيرجودِك من المتلقي القيام بأعمال إضافية بجانب قراءة النص كتحميل تطبيق على الهاتف

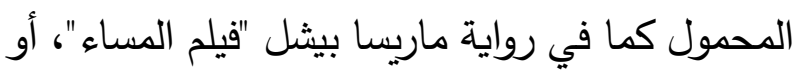
متابعة الملاحظات الهامشية والتلويحات على الإنترنت كما في رواية مارك مارينو "تلويحات في مكتبة بابل". 
وقائمة الفهرس (دانييلفكي 2000، ص 663- موقع دانييلفكي والمحتوي على نقاشات مرتبطة 705)، وانتهاءً بالمنتدى الإلكتروني الموجود على بالكتاب.

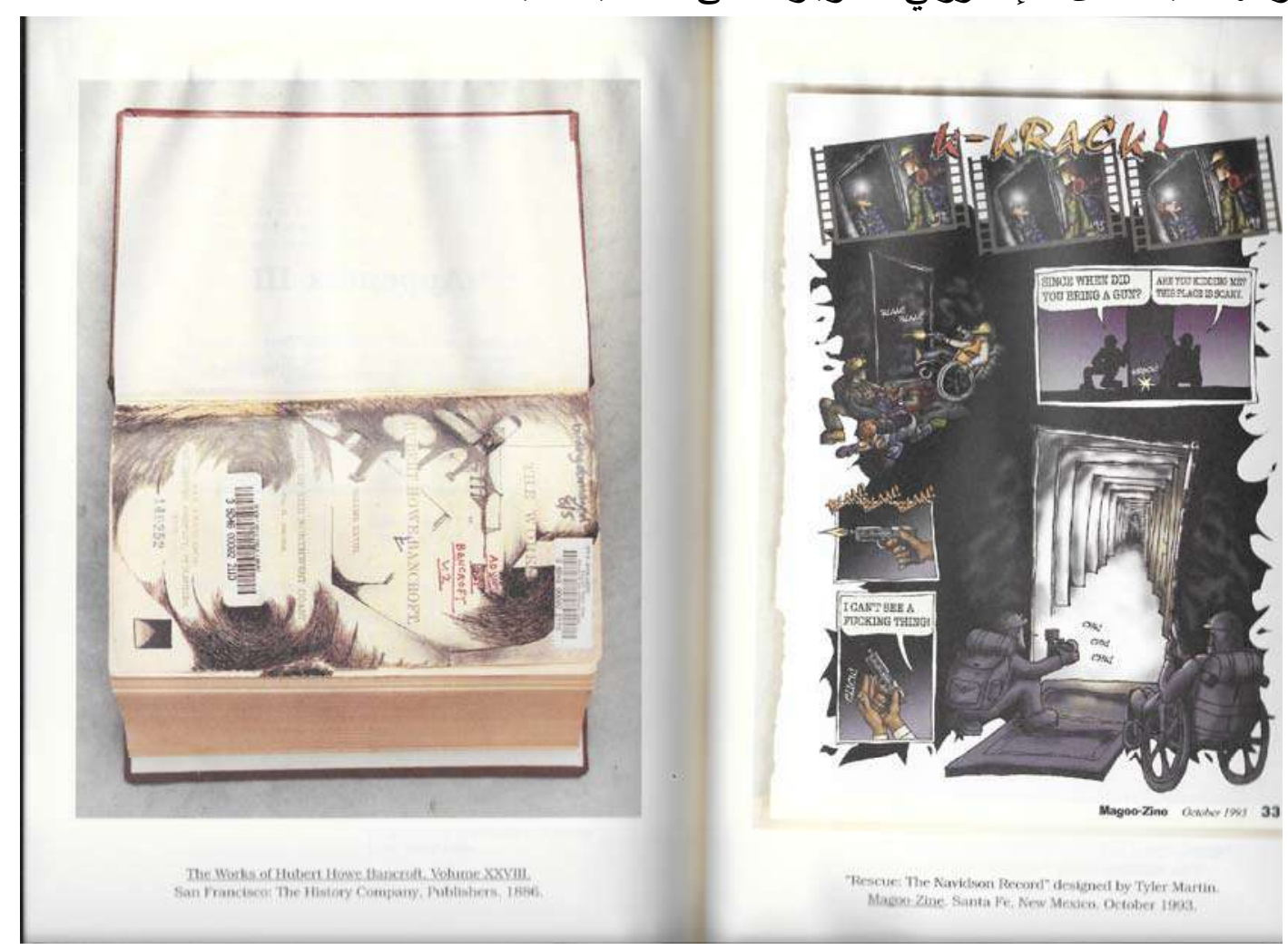

شكل 3. صور في جزء الملاحق من رواية "بيت أوراق الثجر". الصورة الثانية رسم لتقرير نافيسون"

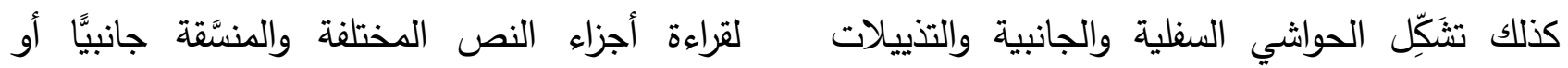
المنتشرة في كل اتِجاه وطريقة عرضها على صفحات بالمقلوب، الأمر الذي قد يشعره بالدوار أثناء القراءة

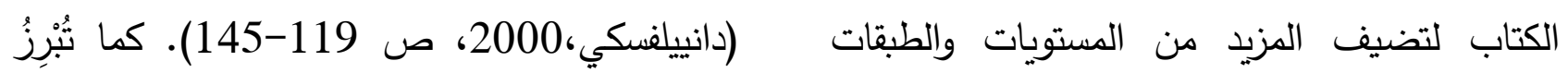

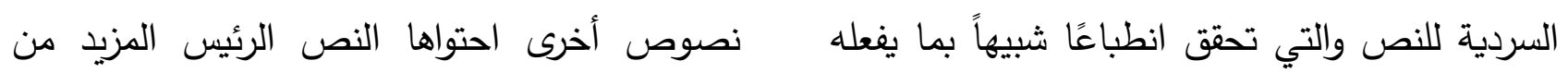

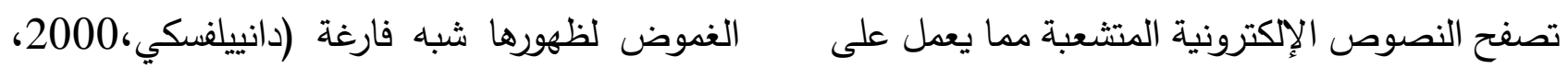
تشويش المتلقي وخلق صعوبة لديه في قراءة جميع ص 190-245) فيما عدا ما حوته من بضع سطور

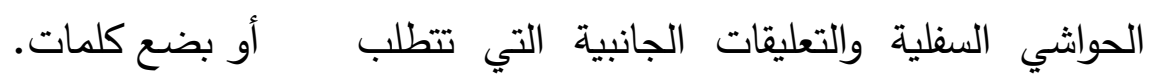
تحريك الكتاب يمنة ويسرة وقلبه إلى الأعلى والأسفل 
مجلة جامعة الملك عبدالعزيز: الآداب والعلوم الانسانية، م29ع3 ص ص: 28- 54 (2021م)

DOI:10.4197/Art.29-3.2

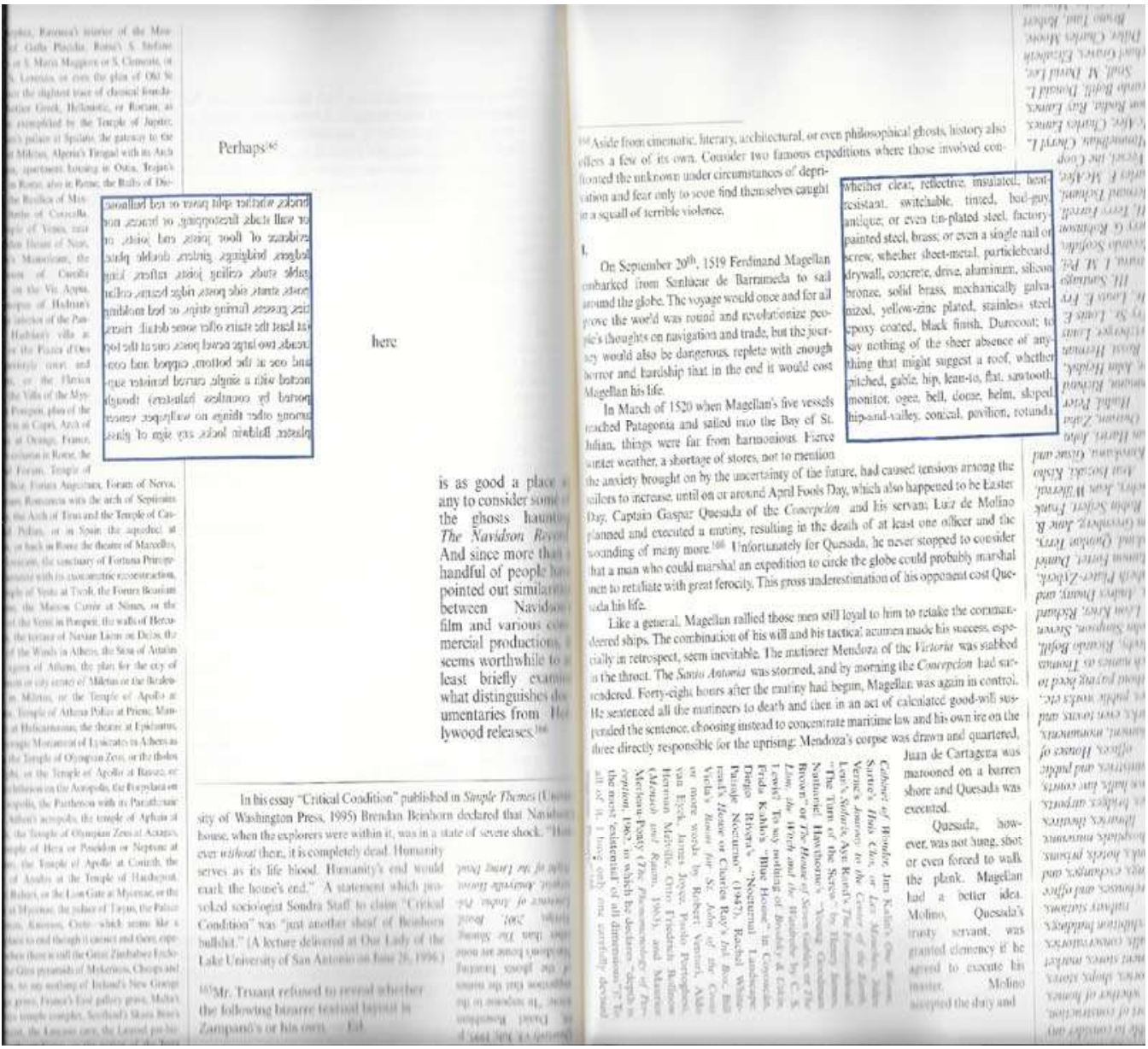

شكل 4. صفحة من رواية "بيت أورلق الثجر" تعكس الطبقات السردية للنص وهي تثبه متاهة بيت نافيدسون 


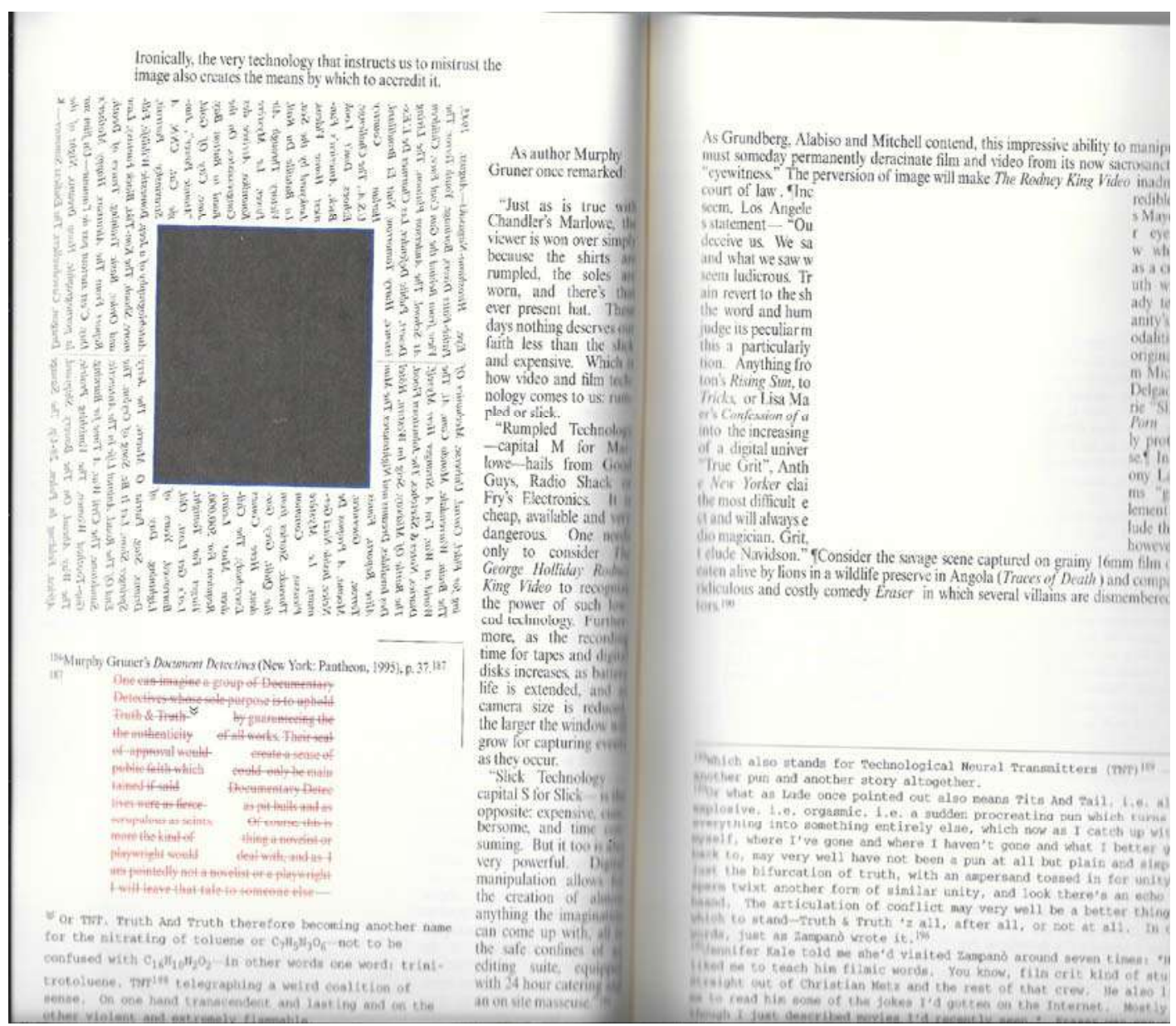

شكل 5. صفحة من رواية "بيت أورلق الثجر" توضح تباين الخطوط للنصوص السردية المختلفة

الكثير من الوقت والجهد تمامًا كما خسر تروينت نفسه في مقال زامبانو، وكما خسر زامبانو نفسه في الفيلم، وكما خسرت أسرة نافيدسون نفسها في البيت، لأن هذا النص يتعلق وببساطة بعملية القراءة ذاتها. وهذه هي الطريقة التي يفسد بها دانييلفسكي توقعات المتلقي عند قراءته لنص رواية "بيت أوراق الثجر" وهو ما يتجلى في بنية أدب ما بعد الحداثة عمومًا التي تعمل على تفكيك لنظم الحبكة الروائية واستبدالها بمكونات ووسائط بنيوية تعمل على تقويض البديهيات وإحداث فوضى عارمة داخل النص. كما يُدرك المتلقي أنه يُمضي الكثير من الوقت أثناء قراءته للنص في تتبع خيوط السرد علَّه يصل إلى لي معانٍ محتملة للألغاز والرموز الغامضة التي يواجهها واحدًا تلو الآخر، ليجد نفسه في النهاية أمام مغامرة أو تحدٍ كبير يبثُ لديه شعورًا بالرغبة في قراءته مرَّات عدَّة ليتمكن من فهمه، إذ يتطلب ذلك تناول النص، ومقارنته مع ما يعرفه بالفعل سواء من نص القصة الرئيس أو النصوص الأخرى الفرعية، ومن ثم تقييمها وتفسيرها، ليكتثف المتلقي فيما بعد أنه قد تاه في تتبع خيوط النصَّين الرئيسين والنصوص الفرعية وخسر 
مجموعة من الرموز، وربما عملية قراءة بدايات

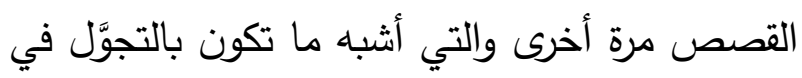
منزل بيزنطي أو في متاهة، إذ تبدو النصوص لهذه

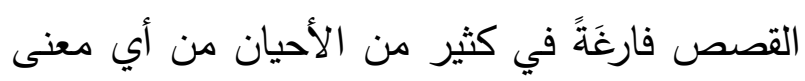
عند إمعان النظر فيها. بالعودة إلى مفارقة الرجل الكفيف - زامبانو- الذي لكي

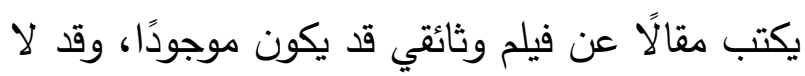

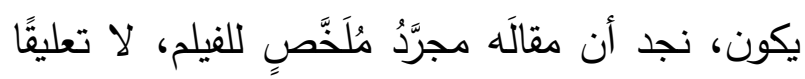

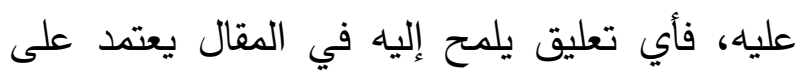

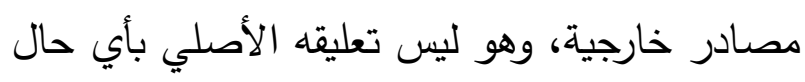

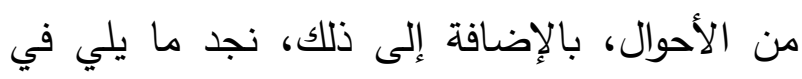
إحدى حواشي جوني تروينت السفلية:

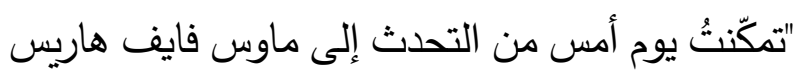
هاتفيًا، هي حاصلة على دكتوراه من جامعة كاليفورنيا، إرفاين في الأدب المقارن ما برحت تعترضئ على على هلى هاهعة

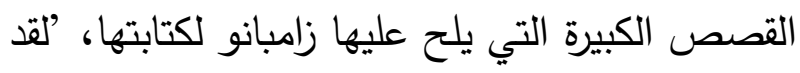
أخبرثُه بأن جميع هذه الفقرات غير ملائمة للعمل

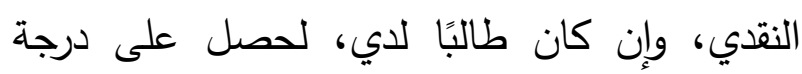
متدنية، لكنه ضحك بينه وبين نفسه واستكمل ما يفعله،

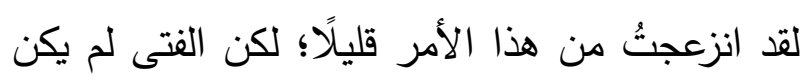

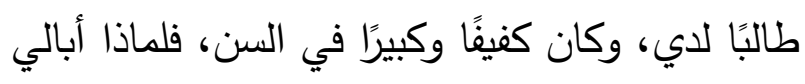

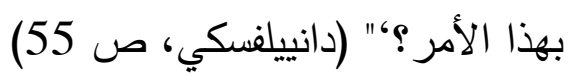
إلى جانب المفارقة والإشكالية في محتوى مخطوطة

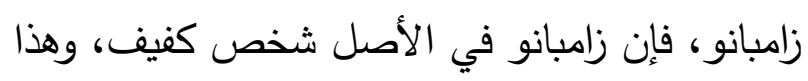
يعني أنه غير قادر على مشاهدة الفيلم في المقام

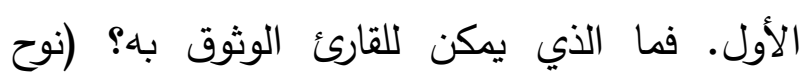

3. المفارقات السردية بالاستمرار في استكثاف رواية "بيت أوراق الثجر "

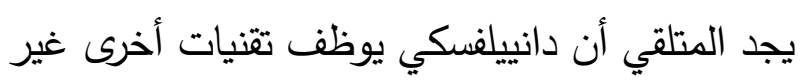
النص الثبكي والتشظي، المفارقات تحديدًا، فهذه المفارقات غنية مثل البيت المذكور في رواية نافيدسون، لكنها وفي تتاقض مباشر مع البيت - الذي مني

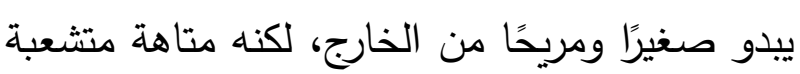

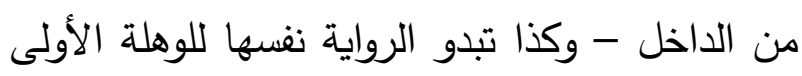
واضحة، إلى أن يتغلغل المتلقي في قراءتها وبتمعَّن

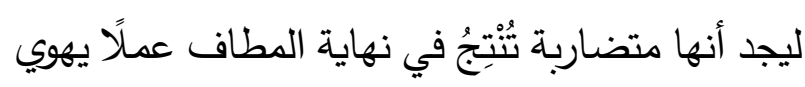
على أساسه فيصبح النص مفرغًا من محتواه. ومن أبرز المفارقات التي تعجُ بها الرواية هي البدايات المتعددة للقصص الرئيسة المختلفة كقصة تروينت وزامبانو ونافيدسون وبالفيينا، فضلًا عن البدايات لرئل

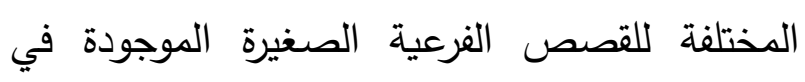
هوامش قصة زامبانو. فحالما يشرع المتلقي في قراءة كل قصة يتوقع أنها ستقوده إلى نهايات محددة، لكنه

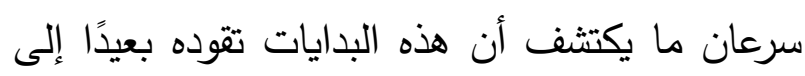
أعمال أخرى ثم توصله في النهاية إلى نهج هيكلي لئل

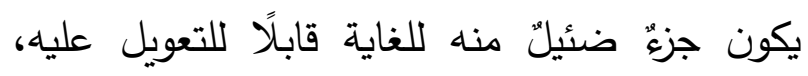
فزامبانو رجل كفيف يكتب عن فيلم قد يكون وقد لا

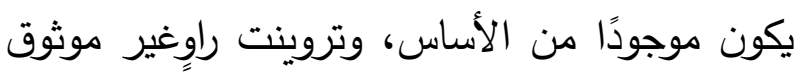
به، أما بيلافينا فهي إما لغز محيّر أو امرأة مجنونة.

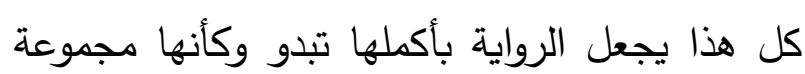

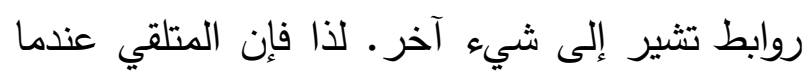

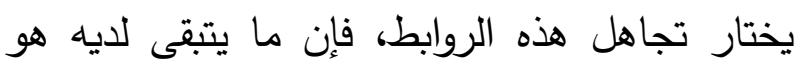


إلى أن الرواية عبارة عن قصة تتحدث عن قصة تتحدث عن قصة، وهذه القصة تتحدث عن بيت يتحدث عن فراغ مبهم في متاهة غامضة الأبعاد مثل كهف أفلاطون المظلم الذي يصوّر من خلاله رحلة الإنسان في البحث عن شمس الحقيقة وسط ظلمة الكهف، إذ يجد المتلقي أن كل ما كوَّنه من معرفة عن الإنس الشخوص والقصص المتعددة في الرواية هي معرفة ظنية وناقصة وأنه وبالرغم من أنه يتعامل مع نص واحد والذي يمكن التعبير عنه مجازًا ببيت وربما شجرة واحدة في الظاهر أو على المستوى اللفظي، إلا أنه وعلى المستوى المجازي يتعامل مع كل صفحة من صفحات النص كأوراق الثجر التي يتخطَُّها الطير أو تهوي بها الريح في مكان سحيق. باستخراج المفارقات المحورية في رواية "بيت أوراق الشجر"، يجد المتلقي أنها تحل كمحور رئيس في عملية قراءة هذا النص، وهذه المفارقات تحديدًا هي تلك السمة التي تجعل المتلقي يشعر بأن ما يقرؤه بين طيَّات هذه الرواية يعكس عالمًا أوسع بكثير مدا قد يشير إليه النص ظاهريًا، لذا فإن ما يقرؤه هو في الواقع كناية عن فعل القراءة بوجه عام، ويتأكد هذا التعبير المجازي عندما نجد أن شخصيات دانييلفسكي أنفسهم يتعاملون مع النصوص على نحو مماثل حيث خسر جوني تروينت وظيفته وغيَّر مجرى حياته نتيجة هوسه بمقال زامبانو، لقد حذا حذو زامبانو - حتى في تقدير النقَّاد الذين يذكرهم في مقاله - فبدت دراسته لرواية نافيدسون ضربًا من ضروب الجنون، يتعلق
2012، ص 12)؛ لذا فإن ما يتبقى أمام المتلقي بعد البحث في هذه المفارقات وطبقات التلميحات المتعددة هو قصص وأحداث مرتبطة ارتباطًا وثيقًا بخيوط من أعمال أخرى - عملٌ فارغٌ في حد ذاته، مُفْرَغُ حتى من نفسه يشير للقارئ من جميع الاتجاهات المختلفة. وهو ما يؤكد شعوره بأن رواية "بيت أوراق الثجر" ترتكز بالكامل على أمرٍ آخر - نصوص أخرى لئ لئ وتلميحات أخرى - بدلًا من الارتكاز على عالمها ونصها الخاص. لذا فإنه من الطبيعي أن تتتامى لدى المتلقي تساؤلاتُ عدة عمّا يتبقى من الرواية لقراءته، وهو ما يشير إليه جيمسون (1991) عن عناصر أدب ما بعد الحداثة المكونة من شبكة معقدة التلميحات والرموز المتراكمة التي تبدو في ظاهرها مجردة من أي قيمة أو معنى حقيقي (ص 37). إذ لم ترد قصة تروينت في المقال إلا على هيئة حَوَاشٍ سفلية. وفي مقالٍ بعنوان: "قراءة كتابٍ عن قراءات شخصٍ ما" (2009)، يلخِصص مارتن بربك تجربة قراءة رواية " بيت أوراق الثجر" على النحو التالي: "على الرغم من أن الحبكة تتناول بيتًا ينمو بلا حدود من الداخل، إلا أن كاتبه يتناول بوضوح عملية القراءة، وهو تعبير مجازي لتفسير الكتب نفسها." (1) وأخيرًا، فإن أحد أهم المفارقات في رواية "بيت أوراق الثجر" هي المفارقة بين عنوان الكتاب وما يشير إليه داخل الرواية، فمن المؤكد أنه يمكن فهم العنوان بوصفه إثارة للبيت نفسه، متاهة بيت نافيدسون، ولكن الأمر يتجاوز ذلك إلى أوراق النص نفسه والتي تثير 
تحمل نقطتين أساسيتين في رواية نافيدسون، وفي حين أن زامبانو ونافيدسون - المحقق البارع - لا يتحدثان في هذا الفصل سوى بعبارات بسيطة مثل: "ما خطب الحيوانات الأليفة؟" (دانييلفسكي، ص 75)، إلا أن الحاشية المتعلقة برواية تروينت تمتد لعدة صفحات ينتقد تروينت فيها زامبانو، ويتقيض في مناقشته قبل أن يشير قائلًا "في الوقت الذي أود أن أقدم لكم تفسيري

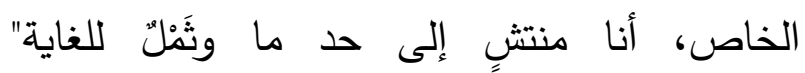
(دانييلفكي، ص 76 1. هذا الاعتراف من قبل تروينت بمخامرة العقل يدل على أنه لا يُمكن للقارئ الوثوق بتروينت لأنه راوٍ معيق لفهم أحداث الرواية. وينعكس ذلك في عباراته وتركيب جمله، فأثناء تتزهه وهو ثمل، يلاحظ وجود كلاب فيستطرد قائلاً: "حسنًا، لا توجد كلاب سوى الكلب البكيني. ولكن هذه قصة أخرى لن أرويها، لا يمكنني أن أروي هذه القصة" (دانييلفكي 2000، ص 77). بعد هذه العبارة يتوقف تروينت عن ذكر الكلب على مدى مئتي صفحة من الرواية، وعندما يتحدث عن الكلب مجددًا، يتضح أن "الكلب البكيني" ليس له أي صلة بمقال زامبانو على الإطلاق، وأنه يروي قصةً من طفولته، عندما شاهد كلبًا يقُتَل على يد مالكه، وهي قصة لا تخبرنا شيئًا عما يدعي تروينت أنه يخبرنا به - أي مقال زامبانو- ولكنه بدلا من ذلك، يخبرنا كثيرًا عن ذهن

$$
\text { تروينت المتشتت. }
$$

من خلال هذا المثال عن قصة الكلب وغيرها من الأمثلة المشابهة، يتمكن المتلقي من تتبع الطريقة التي
ذلك ببنية التعبير المجازي - كيف تويّعُ عملية القراءة العالم المحيط بالمتلقي وتُغَيَرِهْ تغييرًا جذريَّا، ذلك التعبير الذي رأينا من خلاله كيف أفسد دانييلفسكي كلًّ من عناصر أدب ما بعد الحداثة وقواعده السائدة.

\section{4. راوٍ غير موثوق به}

سيتم التركيز في هذا الجزء بشكل خاص على الراوي الرئيس غير الموثوق به في رواية "بيت أوراق الثجر"، وهو جوني تروينت الذي يُعَدُّ (راويًا) غير موثوق به من عدة جوانب. فمن خلال مقارنته بالعديد من الرواة غير الموثوق بهم في أعمال أدبية أخرى، يبدو أن تروينت بارع في تحقيق العديد من السمات المشابهة للرواة غير الموثوق بهم مثل شخصية يوساريان في رواية "هيلر"، أو شخصية هولدن كولفيلد في "رواية سالينجر"، أو حتى شخصية همبرت في رواية "لوليتا" وأليكس في رواية "البرتقالة الآلية". لكن ما يتجاوز ذلك هو أنه من خلال تحليل شخصية تروينت بوصفه راويًا غير موثوق به، فإنّ المتلقي سيتمكن من اكتثاف وجمع المزيد من القرائن التي تساعده على فهم النص وتفسيره، وتحديد تفسيره الذي يمكنه الوثوق به، إذ يثبت تروينت أنه راوٍ غير موثوق به في العديد من الحالات أدناه.

أولًا: يثبت تروينت مرارًا وتكرارًا تَشَتُتَّهُ عن القصة التي يرويها. وخير مثال على ذلك إشارته إلى الكلب البكيني عدة مرات إذ يستحضر تروينت أولاً صورة الكلب استحضارًا عابرًا أثناء مناقشة فصل حيوانات زامبانو، وهذا بمثابة مقطع قصير من صفحة واحدة 
تشوبها عيوب متزايدة، وبالتالي يصعب الوثوق في ما

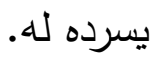

اكتسبت شخصية تروينت تعاطف القُرَّاء بطريقة ما كونه في نهاية المطاف يحمل صفات البَشَر، فعلى لئل الرغم من أنه يدمن الكحول ويتعاطى المخدرات، إلا أن جوانب أخرى متعددة من شخصيته تكثف عيوبه ومشاكله العاطفية التي يحاول معالجتها عن طريق

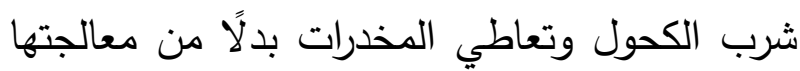
بطرق سليمة، مما يقلل من إمكانية أو احتمالية وثوق المتلقي به، فهو يثكو - مثلًا - من مشكلةٍ في علاقاته الحميمية، خصوصًا مع ثمبر، كما أن لديه مشاكل مع والدته التي يتحاشى باستمرار التعامل

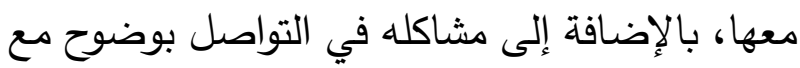
أصدقائه، وينعكس ذلك كله في الطريقة التي ينغلق لإنق بها على نفسه وانعكافه على مقال زامبانو . إلى جانب ذلك، يجد المتلقي أن التطرف هو إحدى سمات تروينت الرئيسة؛ إذ ينعكس ذلك على الطريقة التي يصبح بها مهووسًا بمقال زامبانو، إن شخصية تروينت

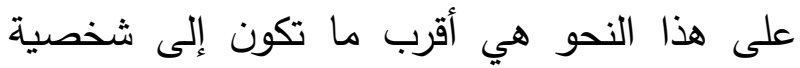
الإنسان العادي الذي يُعَانِي من واحدة على الأقل من

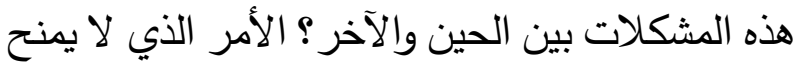
المتلقي رغبة في التفاعل مع شخصية تروينت فحسب - إذ يشعر بالتعاطف تجاهه وتجاه الكيفية التي يتعامل بها مع معاناته، وهنا يبدأ المتلقي في إدراك الجوانب التي يتثاركها معاه-كما أنه يكثف للقارئ أثناء ذلك أبعادًا أخرى لشخصيته.
يعرض بها دانييلفكي شخصية تروينت، حيث يبدأ المتلقي في التعرف على الأمور المهمة بالنسبة إليه (كقصة الكلب وموته الذي أنَّرّ فيه) والأفكار المسيطرة على تفكيره، ويتمثل ذلك في عدم قدرته على التركيز في التفاصيل ذات الصلة خصوصًا عندما يكون مثقلًا بأمر عاطفي، ورغم أن المتلقي يدرك ذلك عن

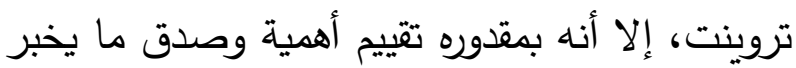
به تروينت من خلال ما عرفه عن شخصيته وعن أسلوب تتاوله للأحداث المختلفة التي يرويها. ثانيًا: يخبر تروينت مرارًا وتكرارًا عن تعاطيه المخدرات

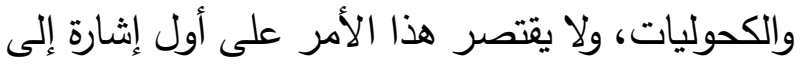
الكلب البكيني فحس، بل يتعدى ذلك إلى مواضع أخرى عديدة في النص بأكمله. فهو يكثف عن

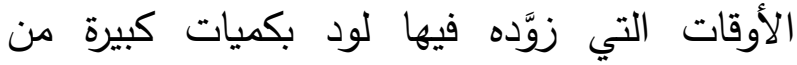

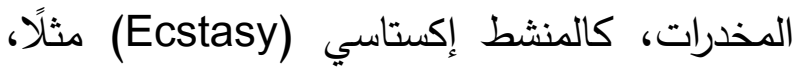
حتى اسم صديقه لود ربما يكون تلميحًا لتعاطي المخدرات، وتحديدًا مهدئ كواليود (Quaalude). وكذلك يشير تروينت بانتظام إلى مدى نَثْوَتِته أو سُكْرِه، إذ تعكس الحواشي السفلية التي يكتبها سُكْرَه المتكرر ، كتلك الحواشي المتعلقة بالكلب البكيني. من أمثلة ذلك: يضم الفهرس ما لا يقل عن تسعة وعشرين صفحة تحتوي على كلمة "شراب" (دانييلفكي، 2000، ص 673)، وما لا يقل عن خمسين صفحة أخرى تحتوي على كلمة "sُنْتَشٍ" (ص لص 679). بتنبه

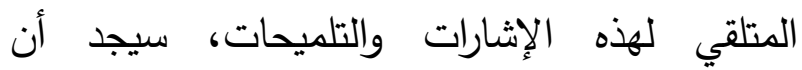
دانييلفكي يصور تروينت على أنه ذو شخصية 
لبصره سيؤدي في أفضل الأحوال إلى عدم دقة التحليل

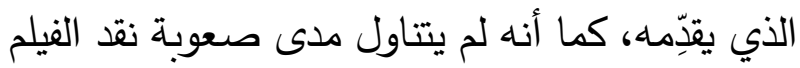

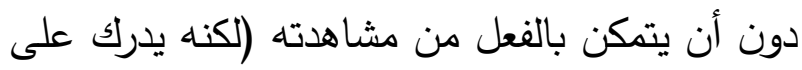

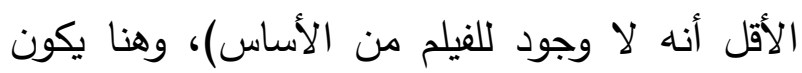

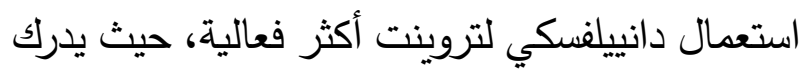

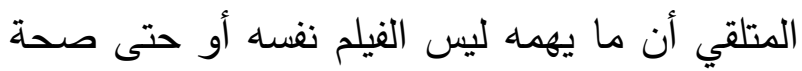
نقد زامبانو من عدمه، ولكن ما يهم فيما يتعلق برواية نافيدسون هو الفكرة ذاتها والتعبير المجازي الرئيس للبيت.

مما سبق يتضح للقارئ كيف أن الأمثلة الآنفة الذكر تساعده على التفاعل مع شخصية تروينت، وعلى تعديل مفاهيمه المتعلقة بسرده القصصي، كما يستنتج المتلقي إن إعادة تقييم الأفراد لذواتهم وللآخرين -وفقاً

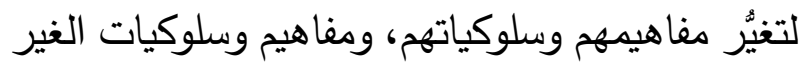
- صفة متأصلة في الطبيعة البشرية، لذا فإن المتلقي يحكم على تروينت، في حين يحكم هو على لود، الأمر الذي يسهم في إحداث تغيير في تصور المتلقي

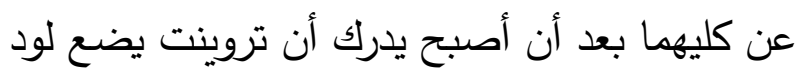

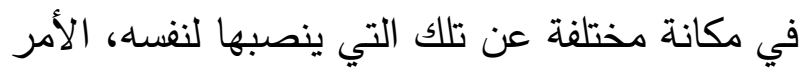
الذي يساعد المتلقي على فهم كيفية تفاعله مع ذكرى زامبانو ورواية نافيدون. ومن خلال هذا التذبذب لتعب العاطفي في شخصية تروينت، يضيف دانييلفسكي طبقة أخرى من المفارقات في شخصية تروينت الراوي والتي تمكن المتلقي من كثف جوانب أخرى في

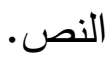

ثالثًا: يلمس المتلقي عدم مصداقية تروينت في مواقفه

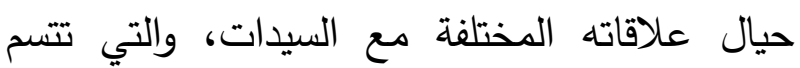

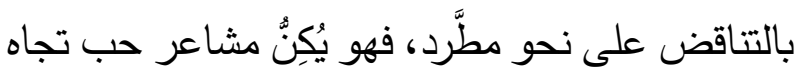

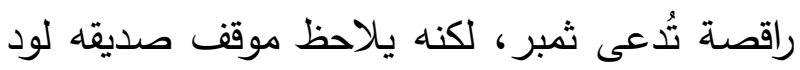
تجاه المرأة وتجاه الآخرين ويقارنها بموقفه عندما يقضيان بعض الوقت سشهر نوفمبر - معًا، حين

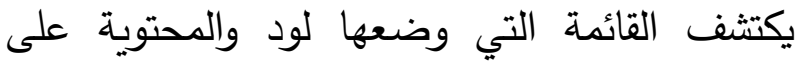
تفاصيل لعلاقاته بأكثر من عشرين امرأة. أما قائمة تروينت فتضم تفاصيل لعلاقته مع ثلاث سيدات فقط، وتنتهي كل منها نهاية حزينة. في ضوء ذلك يقرر تروينت إعادة كتابة وتفسير قائمة لود، ويستعين بالتفاصيل التي ذكرها لود، مثل "كارولين، 21 فتاة سويدية، على آلة نورديك تراك"، ويضيف إليها أمورًا

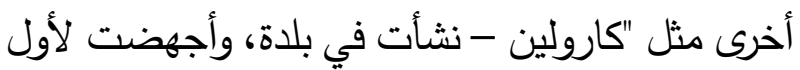
مرة عندما كانت في الثانية عشرة من عمرها"

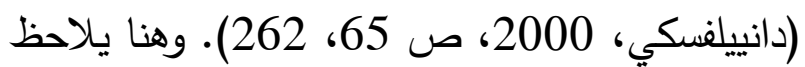
أن تروينت من خلال إعادة كتابة القائمة يقوم بانتقاد لود ويصفه باستغلال الضعفاء وتجاهل احتياجاتهم العاطفية - بينما يتجاهل أنه هو نفسه يتصف بنفس لفاء صفات لود، وبأنه في كثير من الأحيان يقوم بارتكاب الأفعال التي ينتقدها في صديقه. وأخيرًا: يتضح أن تروينت لا يُعول عليه في تحرير

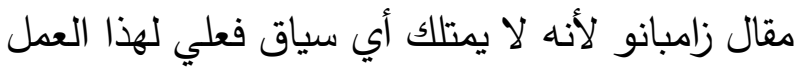

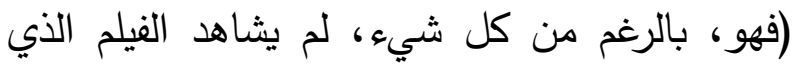

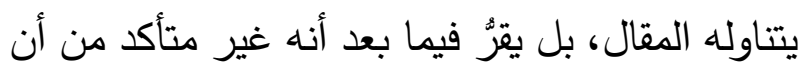
هذا الفيلم حقيقي)، فهو لا يشكك في أن فقدان زامبانو 
للتصديق، وهو ما يعد ركيزة أساسية لتناول أي كتاب

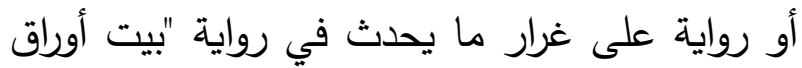

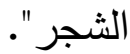

وفي نفس السياق، فإن المقال عن رواية نافيدسون يُعدّ غير جوهري، فيما عدا ما يقوم به من إلقاء الضوء على الطبقات المتعددة من التلميحات إلى نصوص

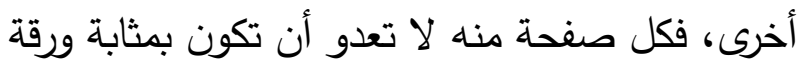

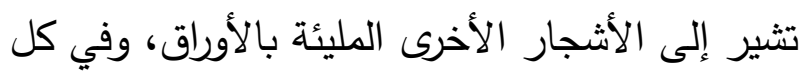

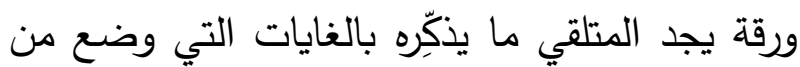

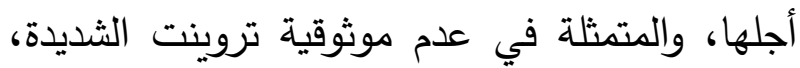
وتذكير للقارئ بأن كل ما قرأه سابقًا هو كناية ذات

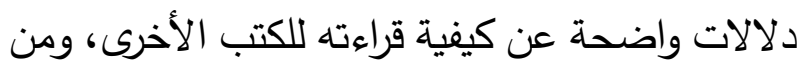

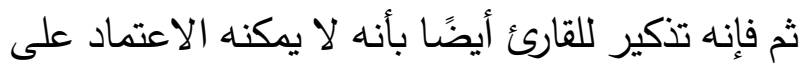
تفاعله مع النص الذي بين يديه فقط، بل إنه لابد من

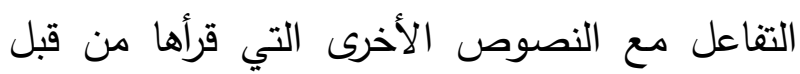

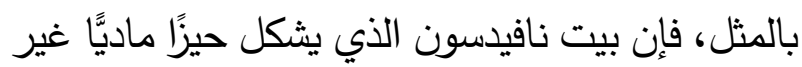
جوهري يرتكز على فكرة البيت (التي يجدها المتلقي

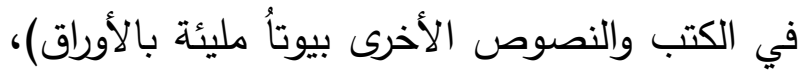

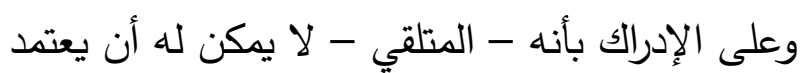

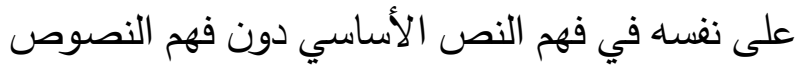

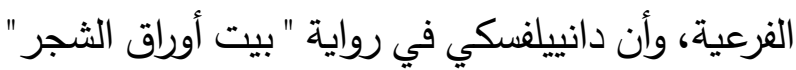

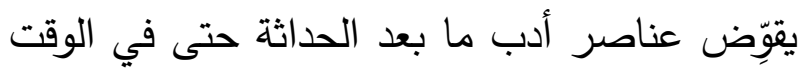

الذي يُظْهِرُ فيه قوتها. 5. ما وراء القص وبنية الإيهام التخيلي لطي فوني

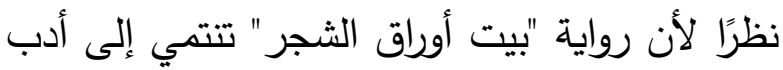

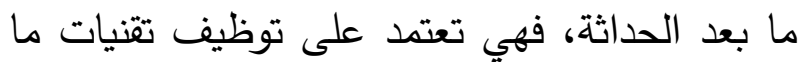

إن إظهار راوٍ غير موثوق به للرواية على أنه أكثر جزء يمكن الوثوق به في الرواية يساعد دانييلفسكي على تقويض هذه السمة المميزة لأدب ما بعد الحداثة، وعلى الرغم من أن هذه السمة حاضرة في كثير من الروايات بغض النظر عن الحقبة الزمنية التي كتبت فيها، إلا إن إدراك المتلقي أنه لا يمكنه الوثوق بمثل هؤلاء الرواة هو العنصر الأساسي والأهم عند قراءة روايات ما بعد الحداثة بشكل عام وفي رواية "بيت أوراق الثجر" على وجه الخصوص، فهذه ليست فكرة جديدة، ولكن الجديد في رواية "بيت أوراق الثجر"

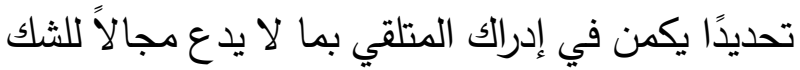
بأنه لا يمكن الوثوق بشخصية تروينت، وعدم الثقة

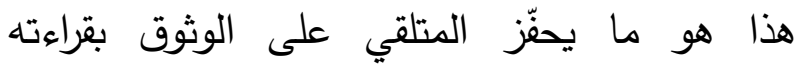
وتقسيراته، فهو يدرك نقاط ضعف تروينت والأفكار

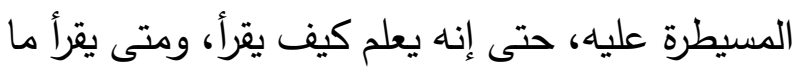
يكتبه تروينت، ليتوصل إلى المفارقات الرئيسة التي تكثف غموض الرواية ذاتها، فيجد أن زامبانو الكفيف ينتقد فيلمًا لا يستطيع مشاهدته، ويجد أن تروينت يعبر عن رأيه في مقالٍ عن فيلمٍ مشكوك في وجوده، مقال كتبه رجل لم يشاهد الفيلم من قبل، كما يجد أن بيت نافيدسون قد يكون أيضًا غير حقيقي (فكيف يمكن أن يكون حقيقيًا والمتلقي قد أصبح على يقين بأن الفيلم الذي يتمور حوله قد لا يكون له وجود، ولم يشاهده أحد؟)، وأن الأمر برمَّته لا يعدو كونه فكرة، بيد أن لان لان القوة تكمن في أن هذه "الفكرة" ترغم المتلقي على لعى التماهي مع النص وإن كان غير معقول أو غير قابل 
يقود ذلك إلى الحديث عن أحد أهم عناصر ما وراء القص في الرواية، وهو عنوان الرواية ذاتها: "بيت أوراق الثجر". ففي كلمة "أوراق" إثارة إلى أوراق لروات داق لتهات

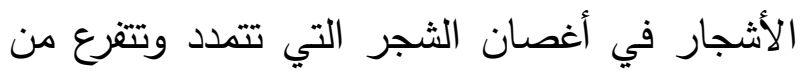
جذورها. وكذلك فإن كلمة "بيت" في عنوان الرواية إثارة إلى بيت نافيدسون الآخذ في التمدد والتثرع في

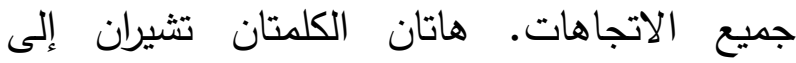
استراتيجية بناء الرواية المكوَّنة من قصة شخص الهص يرويها شخص آخر عثر عليها في مخطوطة ويطلع المتلقي عليها ليجدها مليئة بملاحظاته ومشاعره الثخصية التي وضعها عند قراءة كل فقرة، مما يخلق حالة من الالتباس لديه ويكتثف أثناء القراءة بأن الرواية أكبر من كونها مجرد رواية عادية، بل إنها تتمدد وتتفرع تمامًا مثل أوراق الثجر ومثل بيت نافيدسون ومتاهاته ودهاليزه، إذ لا يمكن له الوثوق بأي من هؤلاء الرواة، خصوصًا حينما يجد أن الرواية تحتوي على بدايات متعددة لقصص متعددة ونهايات مباغتة وغير متوقعة لهذه القصص كاختفاء المتاهة فجأة دون أي تفسير وكقصة الطفل الذي مات فور ولادته (دانييلفكي، 2000، ص ن 518-521) وينتهي الأمر بالمتلقي في إجراء محاولات يائسة

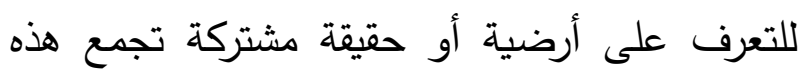
الثخصيات وتربط المكونات الأخرى للرواية. ففي عنوان الرواية صورة مركزية، ليس لهذا الكتاب

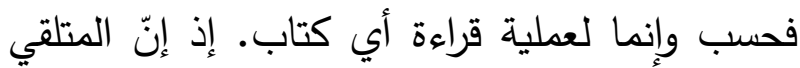
عندما يفتح الكتاب لأول مرة يدخله كما يدخل البيت،
وراء القص كمخاطبة المتلقي مباشرة والتعليق على الكتابة وإقحام شخصيات من كتب أخرى وفي الرواية جاءت مخاطبة المتلقي مباشرة من خلال التحذير الوارد مباشرة في مقدمة الكتاب: "هذا العمل ليس موجَّهًا لك" (دانييلفسكي، الصفحة الأولى)، ثم يجد هيد المتلقي تحذيرًا مشابهًا في الصفحة التالية: "إن الكوابيس تؤرقني، ولأنني أعاني من ذلك كل ليلة فإنني تعوَّدت عليها منذ زمن بعيد، لكن ليس ذلك هو الحال في هذا الكتاب" مثل هذا الخطاب للمتلقي يجعله بمثابة تهيئة وحث له على الاستعداد لما سوف يحتويه النص من عناصر وتقنيات غير تقليدية تستوجب منه العمل على الوعي بها وفهمها وعلى تتبع خيوط السرد المتعددة والمتثابكة التي أنتجت العمل الروائي. كذلك يقوم تروينت بالتعليق في موضع آخر بأنه لا يدري

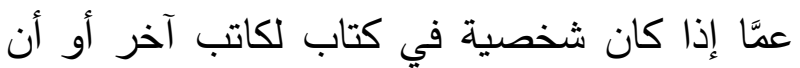
مخطوطة نافيدسون مثلًا هي عمل من محض الخيال (دانييلفكي، 2000، ص 10)، وذلك للفت انتباه المتلقي بأنه على أعتاب نصٍ غير تقليدي حيث يقرأ نصًا داخل النص - مقال زامبانو "مخطوطة نافيدسون" داخل رواية "بيت أوراق الثجر". كما يجد المتلقي مجموعة كبيرة من تعليقات شخصيات الرواية والتي تثير إلى وعيهم التام بذاتهم وبأنهم شخصيات واقعية تعمل داخل نص ذي طابع تخيلي (مصنوع بدقة) مثل بطل الرواية جوني تروينت الذي يسرد قصته - النص الرئيس الثاني في الرواية - أثناء قراءته محتوى مخطوطة نافيدسون. 
للاستهلاك بقراءة الصفحات بسرعة، ينظر نافيدون بتمعُن إلى النص وكلما اقترب من النهاية أسرع في القراءة إلى أن يصل إلى الكلمات الأخيرة هنا تنطفئ النيران التي كانت مشتعلة في يديه، ويتاثر الرماد في الفراغ المحيط، ويخبو اللهب ويخفت إلى أن ينطفئ يختفي الكتاب دون أن يترك خلفه سوى (آثارٍ) غير إن مرئية تختفي بالفعل في ثنايا الظلام (دانييلفسكي، ص لصن 467). فحرق الكتاب يعد كناية عن تقويض دانييلفكي لمقومات أدب ما بعد الحداثة، وعن تناثر أوراق النص في رياح التلميحات، التي لا يتبقى منها سوى "آثار غير مرئية تختفي في ثنايا الظلام." وعند النظر عن كثب، لا يرى المتلقي في تلك الأوراق

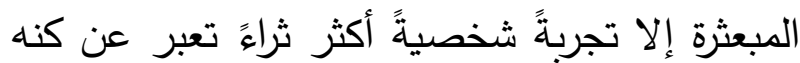

القراءة ذاتها.

كما يستخدم دانييلفكي النصوص التي تثير إلى ذاتها استعمالًا متكررًا ضمن النص العام وعلى غلاف لفالفي الرواية على حد سواء. ففي الفصل الأول، على سبيل

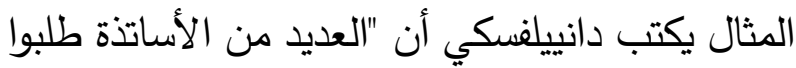
استعراض مخطوطة نافيدسون في ندواتهم التي عقدوها، كما طلبت العديد من الجامعات بالفعل من العشرات من طلابها في مختلف الأقسام قراءة رسالة الدكتوراه التي تتناول الفيلم بالكامل" (دانييلفكي 2000، ص 6). يقول بيمونج معلقاً على إستراتيجية دانييلفكي في هذا الخصوص (2000): "يستخلص دانييلفكي من هذه الدراسات القائمة والخيالية عناصر لا حصر لها لخلق خطاب نظري مستفيض وشامل
وُيبحر في العالم الوارد فيه بقراءة أوراقه الواحدة تلو الأخرى. قد يختار قراءة الكتاب بالترتيب، بالانتقال من البداية نحو النهاية بقراءة ورقة تلو الأخرى؛ لكنه قد يختار أيضًا الانتقال عشوائيَّا من جزء إلى آخر ، تحمل كل صفحة من صفحات هذا الكتاب - أو الورقة - معنى خاصَّا بها، ولا يكتمل بناؤه إلا عند جمع هذه

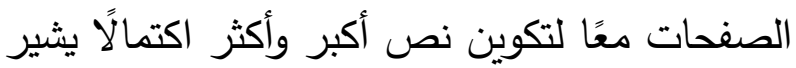
إلى عالم أكبر من جزئياته الصغرى، تمامًا مثل البيت الذي يكتمل باكتمال مجموع ما يحتويهه من غرف وأبنية فرعية. وعند مقارنة هذه الصورة بالقصيدة التي أوردها دانييلفكي في ذيل رواية "بيت أوراق الثجر": "السلوان مصير / من يحزنون/ عندما تتجرف الأفكار

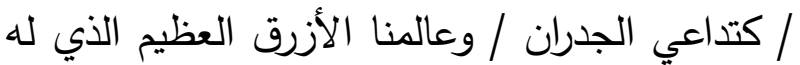

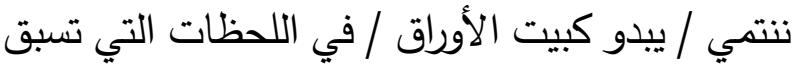
العاصفة" (دانييلفكي، ص 563). فإن الإثارة إلى

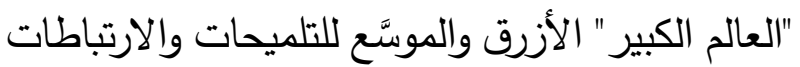
الثبكية تتكرر من جديد لكن الأهم من ذلك تبعثر أوراق النص بالمعنى المجازي والحرفي. حيث يعيد هذا المشهد إلى الأذهان مشهدًا من مقال زامبانو حيث حرق نافيدسون صفحاتٍ من النص، وهو ما يرمز إلى اختفاء النص وعدم بقاء شيء منه. وهذا هو حال المتلقي عندما يتناول الرواية فيبدأ بقراءة النص عدة أسطر بِتَرَِّّ، ثم تتسارع وتيرته في القراءة، فينتقل بسرعة من صفحة إلى أخرى كما لو أن النار تنتقل من أطراف أصابعه إلى الصفحات. وهنا تأتي

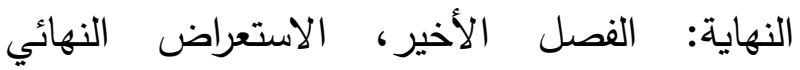


الثجر"، إلا إن معاني تلك الكلمات تُعَدُّ جزًَا لا يتجزأ

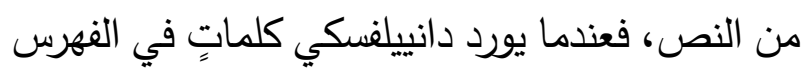
لا تشكل جزءًا من النص نفسه، فإنه يسترعي الانتباه إلى هذه الكلمات، ويكون معنى كل منها بالتأكيد جزءًا

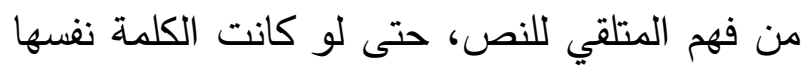

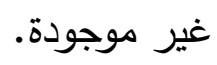
وأخيرًا هناك استعمال دانييلفسكي المتكرر للأكروتيات والرموز الأخرى داخل الكتاب، ونظرًا إلى تكرُر هذه دئه الأكروتيات بكثرة، فسيتم التركيز فقط على عدد محدد الترد

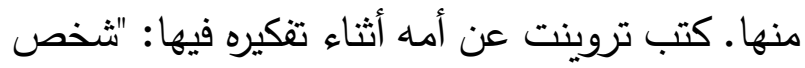

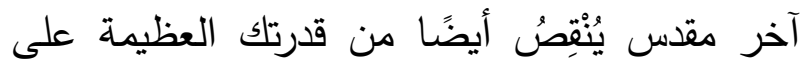
إبطاء الوقت، كما لو كان وصفه بأنه مثل المرأة لئه

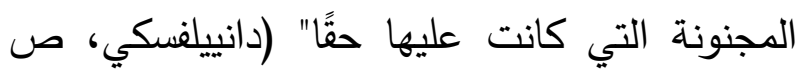
502). فمن هو المقد الآخر؟ باستعمال

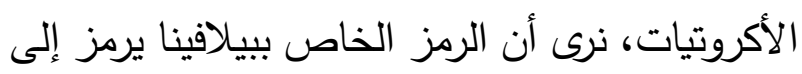

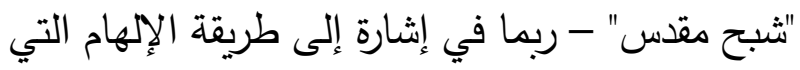

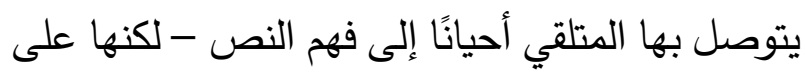

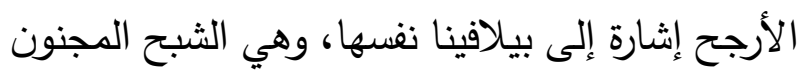

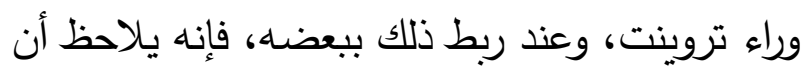
بعض النقّاد ينظرون إلى الخطوط التي اختارها دانييلفكي لعمله، ويجزمون من خلالها بأن بيلافينا هي مؤلّف العمل، ويأتي هذا التفسير من مقابلة أجراها إريك ويتمرهاوس عام 2000 مع دانييلفكي لمجلة منيك فلالك (Flak Magazine)، إذ يقول دانييلفسكي: "هناك سبب وراء اختيار جوني تروينت لنوع الخط المسىى "Courier" (الساعي). الجميع يطلق عليه لهيه
لقصته" (المقدمة، الفقرة رقم 1). هذا هو تحديدًا "الخطاب النظري المستفيض والثامل" الذي يتيح للقارئ - وفق طريقته المرجعية الذاتية - رؤية

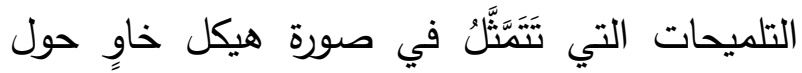

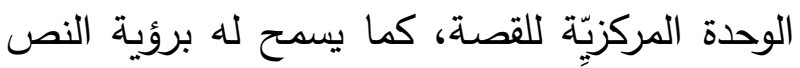
بوصفه إشارة لفعل القراءة. كما يُعد استخدام دانييلفكي للألوان أحد عناصر لمرأة

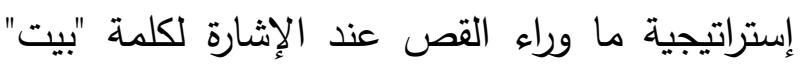
محور الرواية، فكلمة "بيت" في الفهرس الذي لم يظهر في الطبعة الأولى من الرواية كما ورد في مقدمتها لهابها

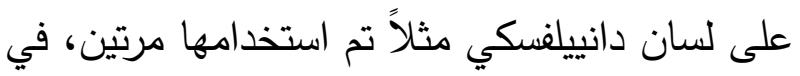
المرة الأولى كُتبت كلمة "أزرق" بجانب كلمة "بيت" وألحق بأسفل الكلمة قائمة طويلة من أرقام الصفحات؛ ثم أعيدت كتابة كلمة "بيت" وبجانبها كلمة "أسود" بينما

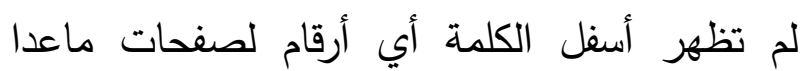
حروف DNE (دانييلفكي، ص 680). وفي الفهرس

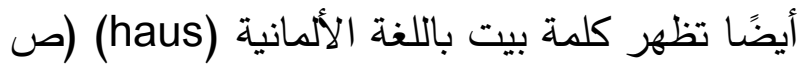
678) وقد كتب بجانبها كلمة "أزرق" بين قوسين وأرقام

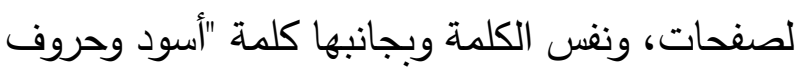
DNE دون إثارة إلى أي صفحات ويتكرر ذلك عند كتاية كلمة "بيت" باللغة الفرنسية (ص 685) ـ وبالمثل ظهر في الفهرس مجموعة من الكلمات المصنّفة التي لا تظهر في النص الروائي ذاته، والتي من ضمنها:

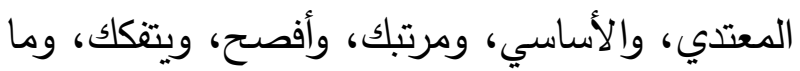

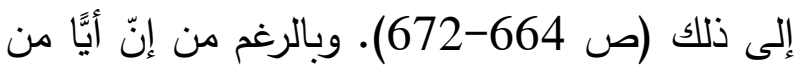
هذه الكلمات غير موجودة في نص رواية "بيت أوراق 
كما يُيرز دانييلفكي في روايته "بيت أوراق الثجر"

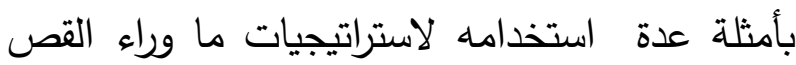
والتتاص كأساليب متّبعة في روايات ما بعد الحداثة لتعزيز العمل بانتهاك وحدة وتماسك النص ولخلق التماهي بين الواقع المكوّن من نصوص نظرية ولتئ وعلمية

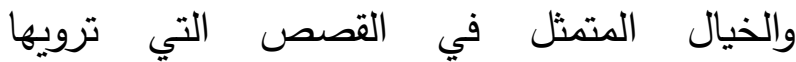
الثخصيات، فالتلميح إلى نصوص ونظريات خارج العمل الأدبي نفسه يضفي على الرواية عمقًا استثائيًا يتيح للقارئ المشاركة في تنكيك الطبقات الهتعددة للنص والتفاعل بشكل أكبر مع الكتاب لمحاولة إيجاد العلاقات بين النصوص بعضها بعضا، فعلى سبيل المثال اشتمل الكتاب على إشارات مباشرة أو تلميحات ضمنية كالتلميح الصريح في الحواشي والتنييلات لكقال فرويد "الغرابة"(The Uncanny) ليشير إلى فئل الأحداث والتطورات الغريبة التي حصلت في غرف لئن منزل نافيسون (دانييلفكي 2000، ص 4)، 20، 24، 98)، (نوح 2012، صناف20) كما يسهب دانييلفكي

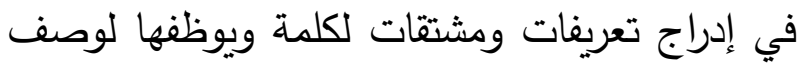
الحالات النفسية لثخصيات الرواية الناجمة عن الإحساس بعدم القدرة على إيجاد تنسير للظاهرة الغريبة في الهنزل أو الناتجة عن القصور الفكري الناتج عن محاولة لفهم قضايا وجودية وفلسفية

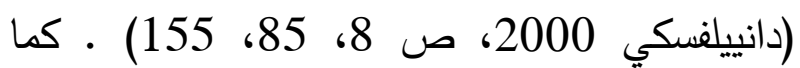
تحتوي الرواية أيضًا على كم كبير من العتبات النصية التي يستهل بها دانييلفكي كل فصل من فصول الرواية لأغراض متعددة مثل أغنيات البيتلز
النوع العادي أو الخط العادي للآلة الكاتبة، لكنه الخط

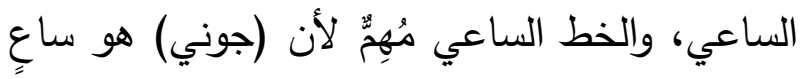

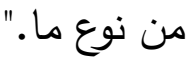
من هنا يستطيع المتلقي التوصل إلى عددٍ من الته الاستتناجات منها أن الصفحة الأولى التي طبعت التى

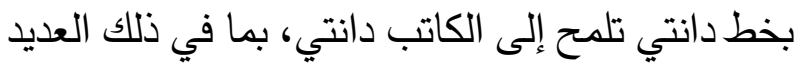
من التلميحات الضمنية في النص نفسه إلى الجحيم بمعناه المجازي العام ومعناه الخاص المتمثل في لفي قصيدة دانتي، وقد أسبب داوسون في إيجاد العلاقة بين هذين النصين في عدة مواقع ربما كان أبرزها تصوير دانييلفكي لثخصية تروينت والصدمات النفسية التي واجهها في علاقاته بالفتاتين جوني ولود وذكرياته عن الفتاة المراهعة من هايتي التي هي أشبه ما تكون بالعبور إلى الجحيم أو المجهول (داوسون، 2015، ص 289). وكنلك فإن قيام دانييلفكي التيكي بتوظيف خط "Courier" (الساعي) الذي يستعمله تروينت بوصفه قارئ ومحرر مخطوطة نافيدسون

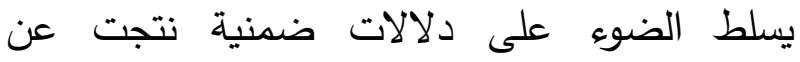
استخدامه أيضًا: فهذا النص في صميمه يشير إلى فلى فعل القراءة لمخطوطة نافيسون؛ مما يجعل تروينت يحمل صفة الساعي أو همزة الوصل بين كاتب المخطوطة زامبانو وبين المتلقي، كما أنّ استخدام خط دانتي لنص والدة ترويتت بيلافينا، تلك المرأة المجنونة أو شبحه الذي يطارد ماضيه وحاضره يؤكد - الخط ذاته المستعمل على صفحة العنوان الأمر يعزز فكرة الجحيم التي تم شرحها آنفاء. 
نصوص أدب ما بعد الحداثة-: "تجربة مرعبة ومبهجة" في آن واحد كونها لا تشير إلى أي عمق في المعنى (جيمسون، ص 34)، ويعود السبب في ذلك إلى حد كبير إلى الطريقة التي يستعمل بها دانييلفسكي بعض العناصر الأدبية الأكثر شيوعًا في فترة ما بعد الحداثة، ث إلى قلبه تلك العناصر رأسًا على عقب، فكل خصائص أدب ما بعد الحداثة - التشعب الثبكي للنص والتشظي والمتناقضات المتعددة، والرواة المتعددون غير الموثوقين، والرموز، والقص الماورائي - تشكّل طبقات من المعاني التي قد تبدو سطحية ومفككة تعمل على تشتيت المتلقي، ولكنه ومن خلال تقصِّيه الواسع النطاق لهذه المعاني فإنه سرعان ما يجد عالَمًا أكثر ثراءً وعمقًا وواقعية مما كان يتخيله على الرغم من تعقيد وصعوبة فهم هذه المعاني، خصوصًا عندما يبدأ تدريجًّا في العثور على مفاتيح الرموز التي توصِله في النهاية إلى أحد أهم هذه الرموز وهي أنّ "بيت أوراق الشجر" هو عبارة عن "فكرةٍ" وليس "ثينًا". وفيما يتلمَّس المتلقي طريقه خلال النص، فإنه يجد نفسه يجاهد للمُضِيّ قُدُمًا فيه، وتضطرُه هذه المجاهدة إلى خلق روابط بين أجزاء العمل التي تبدو متباينة، ومن خلال هذه الروابط الموجودة في العمل المُجزّأ إلى أجزاء أخرى من العمل ذاته وإلى أعمال أخرى - يجد المتلقي نفسه في مواجهة مفارقات متعددة. ومثل رجلٍ كفيف يعتمد على حاسة اللمس والسمع والذاكرة في شق طريقه إلى وجهته، فإن المتلقي يعتمد على هذه المفارقات لإعادة النظر في
"النجدة"(Help) و "يوم في الحياة" (A Day in Life) التي جاءت في الفصل الأول والتي تشير كلماتها إلى فيلم "مخطوطة نافيدسون" في قصة زامبانو (دانييلفكي 2000، ص 3) فضلَ عن العديد من العتبات النمِّية الأخرى لكتَّاب وشعراء وفلاسفة مثل ماري شيلي و فيرجيل وآينشتاين، وتعريفات لكلمات وعبارات من القاموس مثل تعريف كلمة "النجدة" SOS) التلميحات داخل أجزاء الرواية لا تثير فقط إلى مكانة الكاتب الفكريـة والأدبية، بل تضفي على النص أبعادًا تاريخية وفكرية وفلسفية تعمَّق الثيمات وتسهم في رسم شخصيات الرواية، كما تضم الرواية "بيت أوراق الشجر" شبكة كبيرة من فقرات لأعمال العديد من الكتاب مثل سارفانتس وبروست وبورخيس وتشيخوف وآخرين، وكذلك يستحضر العديد والأعمال الفلسفية مثل جوته وهيديجير ويونج وفرويد وديريدا، ويشير كل ذلك بدوره في نهاية المطاف إلى فعل القراءة ذاته بوصفه البيت الذي حدثت فيه هذه الرواية وما تترتب عليه انعكاسات هذه المفاهيم الكونية والفلسفية والثقافية على التجارب الإنسانية التي تستدعيها الرواية لاستجواب ماهيتها وقيمتها في ظل تلك الفوضى والعبثية التي تمكن النص من فرضها على المتلقي طوال الخاتمة في ختام هذا البحث يمكن القول بأن قراءة كتاب "بيت أوراق الشجر" -كما يعبّرِ فريدريك جيمسون عن قراءة 
الاستقرار والتتفق المستمر للغة" (ص 1). والمتلقّي

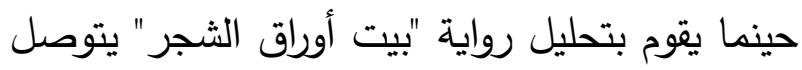
إلى فكرة البيت - وهي فكرة مجردة - وإلى صورة بيت الأوراق وفعل القراءة ذاتها المتمثلة في كل من عملية

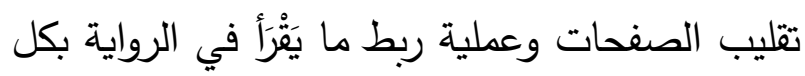

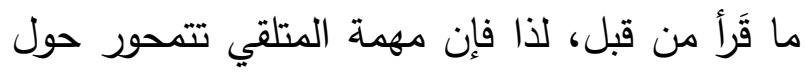
إعادة النظر في طرق وأساليب فهم ما يُقرأ، والمتلقي لئي

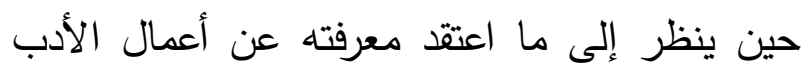
عامة وعن أعمال ما بعد الحداثة وتلك الرموز

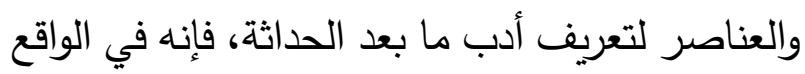
يجد في رواية "بيت أوراق الثجر" ما يلزمه لإعادة

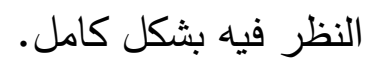

ينتقد دانييلفكي هذه الرموز والعناصر من خلال قلبها رأسًا على عقب ليجبر المتلقي على إعادة تقييم طريقة

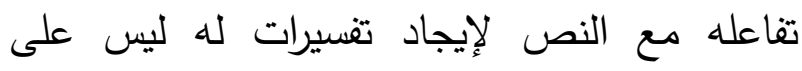
المستوى اللفظي فحسب بل على مستوى المضامين

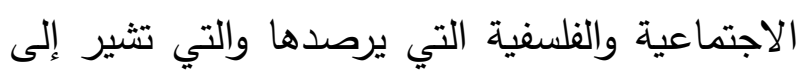
عالم اختلت فيه جميع الموازين المنطقية التي كان يستند إليها المتلقي في تأويله للنصوص التقليدية،

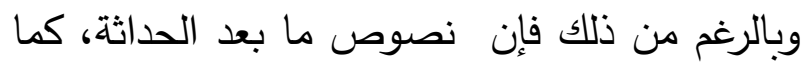
يوضح جيمسون، بإمكانها أن تُتج معانٍ أكثر زخمًا لقدرتها على استحضار فضاءاتٍ جديدة تتبثق من

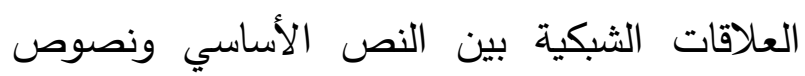
أخرى، وهي ترتكز في ذلك على مدى نجاح المتلقي

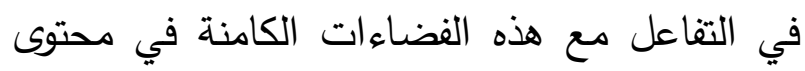

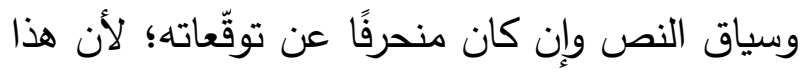

كل ما كان يظن معرفته عن عالم "بيت أوراق الثجر"

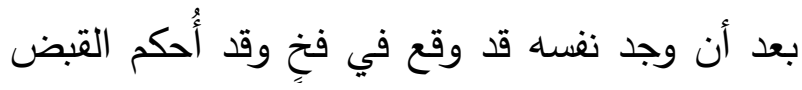
عليه ولا يجد مفرًا منه سوى الخضوع والاستسلام من أجل إتمام رحلته في البحث عن المعنى، فالمتلقِّي يدرك أن كل شيء عرفه عن عالم الرواية غير موثوقٍ به، فكل ما يعرفه عن تروينت وزامبانو وحتى عن أسرة عانِ

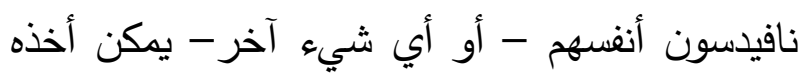
على محمله الظاهر ، ولا يمكن الوثوق بباطنه مطلًَا،

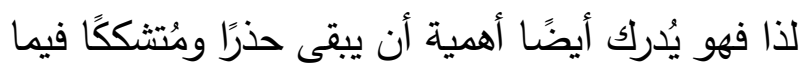

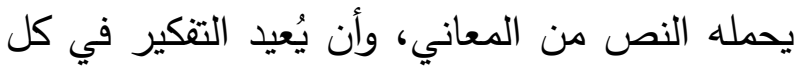

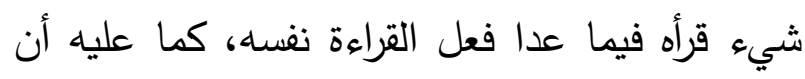
يتساءل عن الصِّلات التي وضعها - ما بين تروينت وبيلافينا، وبين تروينت وثمبر ، وبين تروينت ولود، وبين تروينت وزامبانو، وبين زامبانو ونافيدسون، وبين وبنين أسرة نافيدسون والبيت - لأن كل ما هو مكتوب في ونياني "بيت أوراق الثجر" مبعثر ومتناثر كأوراق الثجر

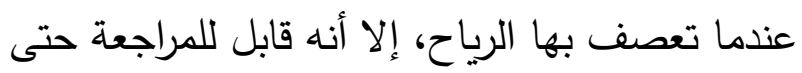
يتمكن المتلقي من ربط الجزئيات ببعضها ليكتثَف

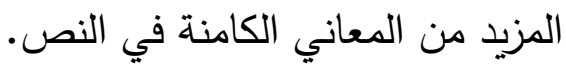
على المتلقِي أن يفكّك مكونات رواية "بيت الأوراق" حتى يشرع في فهمها، فهو عندما يباشر تحليل أجزاء الرواية لرؤية جميع النقاط من الخارج - وهي كلها موجودة تقريبًا على هيئة شبكة من المفارقات والتلميحات - حينها فقط يبدأ في إدرالك ما يتبقى: وهو هنياه الرموز • يقول ثروجمورتن (2009): "إن بيت أوراق

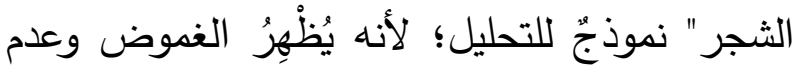


لاحقًا أن عملية البحث هذه هي الاستعارة الأساسية لفعل القراءة ذاتها، بالإضافة إلى ذلك فإن هذا التقويض لتوقّعات المتلقي تحديدًا هو ما يجعل من دالإصن

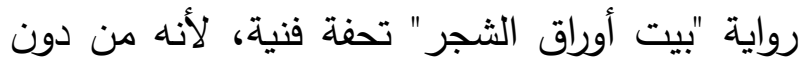

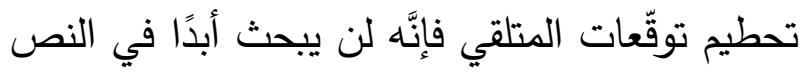
بتلك العزيمة والإصرار، ولن يضطر أبدًا إلى إعادة

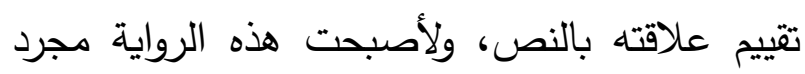

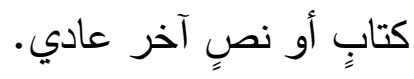

\section{References}

Aarseth, E. (1997). Cybertext: Perspectives on ergodic literature. John Hopkins University Press.

Alter, R. (1975). Partial magic: The novel as a self-conscious genre. University of California Press.

Belletto, S. (2009). Rescuing interpretation with Mark Danielewski: The genre of scholarship in House of Leaves. Genre, 42(3), 99-117. https://doi.org/10.1215/00166928-42-3-499

Bemong, N. (2003). Exploration \#6: The uncanny in Mark Z. Danielewski's House of Leaves. Image \& Narrative: Online Magazine of the Visual Narrative, 5. $\mathrm{http} / / \mathrm{www}$.imageandnarrative.be/inarchive/ uncanny/nelebemong.htm

Brick, M. (2004). Blueprint(s): Rubric for a deconstructed age in House of Leaves. University of Sydney.

Brick, M. (2009). Reading the book of someone's reading: Spatial allegories of the reading experience in Danielewski's House of Leaves and Gascoigne's Master FJ. The McNeese Review, 47, 1-17.

Butler, C. (2002). Postmodernism: A very short introduction. Oxford University Press.
الانحراف والتقويض للتوقعات كما هو الحال في رواية دانييلفسكي هو ما يجبر المتلقي على فحص النص بدقة وبتشكك، والتركيز في عملية القراءة، وبدوره فإن هذا التركيز في التفاصيل المخالفة للتوقعات تجعل المتلقي يغفل عن محور النص وهو ما يُتمّم عملية التقويض على وجه التحديد، فبإعادة النظر في كل فل لهن جانب من جوانب علاقته مع النص، وبطبيعة الحال

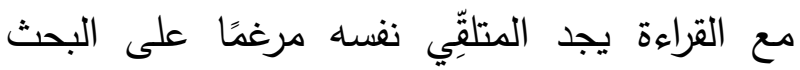

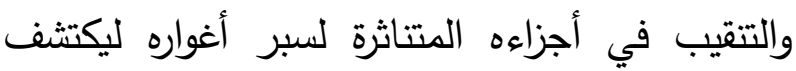

Chanen, B. W. (2007). Surfing the text: The digital environment in Mark Z. Danielewski's House of Leaves. European Journal of English Studies, 11(2), 163-176. https://doi.org/10.1080/1382557070145275 5

Cottrell, S. (2014). "Bold type interview: A conversation with Mark Z. Danielewski."

Cox, K. (2006). What has made me? Locating mother in the textual labyrinth of Mark Z. Danielewski's House of Leaves. Critical Survey, 18(2), 4-15. https://doi.org/10.3167/0011157067806007 56

Danielewski, M. (2000). House of Leaves. Pantheon Books.

Dawson, C. (2015, May 13). "There's nothing so black as the inferno of the human mind: Infernal phenomenal reference and trauma in Danielewski's House of Leaves. Critique: Studies in contemporary fiction, 56(3), 284-298. 10.1080/00111619.2014.905445

Federman, R. (2001). Surfiction: Writing with no restraints. In D. Maus (Ed.). Postmodernism: TheGreenhaven Press companion to literary movements and genres (pp. 66-75). Greenhaven Press.

Genette, G. (1997). Paratexts: Thresholds of interpretation. Cambridge University Press. 
Graulund, R. (2006). Text and paratext in Mark Z. Danielewski's House of Leaves. Word \& Image, 22(4), 379-388. https://doi.org/10.1080/02666286.2006.104 35766

Hagler, S. (2004). Mediating Print and Hypertext in Mark Danielewski's House of Leaves. MODE Literary Journal.

Hamilton, N. (2008). The A-Mazing house: The labyrinth as theme and form in Mark $\mathrm{Z}$. Danielewski's House of Leaves. Critique: Studies in Contemporary Fiction, 50(1), 316. https://doi.org/10.3200/crit.50.1.3-16

Hansen, M. B. N. (2004). The digital topography of Mark Z. Danielewski's House of Leaves. Contemporary Literature, 45(4), 597-636.

https://doi.org/10.1353/cli.2005.0004

Hayles, N. K. (2002). Saving the subject: Remediation in House of Leaves. American Literature, 74(4), 779-806. https://doi.org/10.1215/00029831-74-4-779

Hemmingson, M. (2011, June 9). What's beneath the floorboards: three competing metavoices in the footnotes of Danielewski's House of Leaves. Critique: Studies in contemporary fiction, 52(3), 272287.

https://doi.org/10.1080/00111610903380022

Hermelin, C. D. (2014, March 10). The case of S., or, the metatextual pleasure of ergodic works. The Believer Magazine. http://logger.believermag.com/post/791743 95499/the-case-of-s-or-the-metatextualpleasure-of

Hoffman, G. (2005). From modernism to postmodernism: Concepts and strategies of postmodern Americamn fiction. Rodopi Editions.

Hutcheon, L. (1988). A poetics of postmodernism: History, theory, fiction. Routledge.

Iser, W. (1978). The implied reader: Patterns of communication in prose fiction from Bunyan to Beckett. John Hopkins University Press.
Jameson, F. (1991). Postmodernism, or, the cultural logic of late capitalism. Duke University Press.

Little, W. G. (2007). Nothing to write home about: Impossible reception in Mark. Z. Danielewski's House of Leaves. In N. Brooks \& J. Toth (Eds.), The mourning after attending the wake of postmodernism (pp. 169-201). Rodopi.

Lord, N. (2014, August 6). The labyrinth and the lacuna: Metafiction, the symbolic, and the real in Mark. Z. Danielewski's House of Leaves. Critique: Studies in contemporary fiction, 55(4), 465-476.

https://doi.org/10.1080/00111619.2013.791 242

McCaffery, L., \& Sinda, G. (2003). Haunted house-An interview with Mark Z. Danielewski. Critique: Studies in Contemporary Fiction, 44(2), 99-135. https://doi.org/10.1080/0011161030959994 0

McHale, B. (1987). Postmodernist fiction (3rd ed.). Routledge.

Noah, J. (2012) House of Leaves: The end of postmodernism.

https://digitalcommons.buffalostate.edu/cgi/ viewcontent.cgi? article $=1003 \&$ context $=$ eng $\underline{\text { lish theses }}$

Pohlmann, S. (2012). Revolutionary Leaves: The fiction of Mark Z. Danielewski. Cambridge Scholar Publishing.

Pressman, J. (2006). House of Leaves: Reading the networked novel. Studies in American Fiction, 34(1), 107-128. https://doi.org/10.1353/saf.2006.0015

Quigley, M. (2015). Modernist fiction and vagueness: philosophy, form, and language. Cambridge University Press.

Skordoulis, C., \& Arvantis, E. (2008). Space conceptualization in the context of postmodernity: Theorizing spatial representations. International Journal of Interdisciplinary Social Sciences, 3(6), 105113. 
Stöckl, H. (2005). Typography: Body and dress of a text - a signing mode between language and image. Visual Communication, 4(2), 204-214.

https://doi.org/10.1177/1470357205053403

Throgmorton, M. (2009) House of Leaves:

Navigating the labyrinth of the deconstructed novel. http://scholarlycommons.obu.edu/cgi/viewc ontent.cgi? article $=1076 \&$ context $=$ honors $\mathrm{t}$ $\underline{\text { heses }}$

Wittmershaus, E. (2000). Profile: Mark Z. Danielewski. Flak Magazine.

\title{
Narrative Strategies in Postmodern Literature: The Example of Mark Z. Danielewski's House of Leaves
}

\author{
Laylaa Mohammed
}

\begin{abstract}
Mark Z. Danielewski's House of Leaves, one of the most compelling works in contemporary fiction. The study closely examines Danielewski's unique style of employing a wide array of postmodern narrative elements in his work: fragmentation, hypertextual structure, paradox, unreliable narration, and metafiction. The study demonstrates that whereas Danielewski innovatively uses these postmodern narrative strategies, what makes his work unique lies in the way he subverts these elements. The study further argues that by foregrounding the readers' role as an active participant in the construction and deconstruction of the text, Danielewski not only challenges the readers' process of interpreting the text, but calls into question the existing scholarly discourse revolving around the construction and interpretation of postmodern literature, thereby announcing the death of postmodernism and the birth of the new trend of post-postmodernism.
\end{abstract}


استراتيجيات السرد في أدب ما بعد الحداثة: رواية "بيت أوراق الثجر" لمارك ز ـ دانييلفكي أنموذجًا 